\title{
A Brainstem Neural Substrate for Stopping Locomotion
}

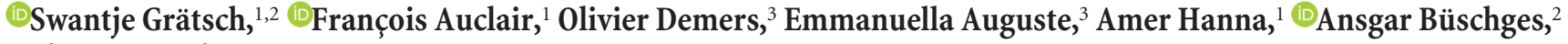 \\ and Réjean Dubuc ${ }^{1,3}$ \\ ${ }^{1}$ Department of Neuroscience, Université de Montréal, Montréal H3C 3J7, Québec, Canada, ${ }^{2}$ Department of Animal Physiology, Institute of Zoology, \\ University of Cologne, Cologne 50674, Germany, and 32Department of Sciences de l'Activité Physique, Université du Québec à Montréal, Montréal H3C 3P8, \\ Québec, Canada
}

Locomotion occurs sporadically and needs to be started, maintained, and stopped. The neural substrate underlying the activation of locomotion is partly known, but little is known about mechanisms involved in termination of locomotion. Recently, reticulospinal neurons (stop cells) were found to play a crucial role in stopping locomotion in the lamprey: their activation halts ongoing locomotion and their inactivation slows down the termination process. Intracellular recordings of these cells revealed a distinct activity pattern, with a burst of action potentials at the beginning of a locomotor bout and one at the end (termination burst). The termination burst was shown to be time linked to the end of locomotion, but the mechanisms by which it is triggered have remained unknown. We studied this in larval sea lampreys (Petromyzon marinus; the sex of the animals was not taken into account). We found that the mesencephalic locomotor region (MLR), which is known to initiate and control locomotion, stops ongoing locomotion by providing synaptic inputs that trigger the termination burst in stop cells. When locomotion is elicited by MLR stimulation, a second MLR stimulation stops the locomotor bout if it is of lower intensity than the initial stimulation. This occurs for MLR-induced, sensory-evoked, and spontaneous locomotion. Furthermore, we show that glutamatergic and, most likely, monosynaptic projections from the MLR activate stop cells during locomotion. Therefore, activation of the MLR not only initiates locomotion, but can also control the end of a locomotor bout. These results provide new insights onto the neural mechanisms responsible for stopping locomotion.

Key words: brainstem; lamprey; locomotion; locomotor termination; mesencephalic locomotor region; reticulospinal neurons

Significance Statement

The mesencephalic locomotor region (MLR) is a brainstem region well known to initiate and control locomotion. Since its discovery in cats in the 1960s, the MLR has been identified in all vertebrate species tested from lampreys to humans. We now demonstrate that stimulation of the MLR not only activates locomotion, but can also stop it. This is achieved through a descending glutamatergic signal, most likely monosynaptic, from the MLR to the reticular formation that activates reticulospinal stop cells. Together, our findings have uncovered a neural mechanism for stopping locomotion and bring new insights into the function of the MLR.

\section{Introduction}

Locomotion occurs in bouts of activity that must be efficiently started, maintained, and stopped. In vertebrates, the spinal cord

Received Aug. 2, 2018; revised Nov. 20, 2018; accepted Dec. 3, 2018.

Author contributions: S.G. and R.D. wrote the first draft of the paper; S.G., F.A., A.B., and R.D. edited the paper; S.G., F.A., A.B., and R.D. designed research;S.G., F.A., 0.D., E.A., and A.H. performed research;S.G., F.A., A.B., and R.D. analyzed data; S.G. and R.D. wrote the paper.

This work was supported by the Canadian Institutes of Health Research (Grant 5129 to R.D.); the Natural Sciences and Engineering Research Council of Canada (Grant 217435 to R.D.); and the Great Lakes Fishery Commission (Grants 54021 and 54035 to R.D.). S.G. received scholarships from the University of Cologne and the German Academic Exchange Service. We thank Danielle Veilleux for technical assistance, Frédéric Bernard for help with the graphics, and Dimitri Ryczko for valuable discussions.

The authors declare no competing financial interests.

Correspondence should be addressed to Réjean Dubuc at rejean.dubuc@gmail.com.

https://doi.org/10.1523/JNEUROSCI.1992-18.2018

Copyright $\odot 2019$ the authors $\quad 0270-6474 / 19 / 391044-14 \$ 15.00 / 0$ contains neural networks that generate the muscle synergies essential for body propulsion (for review, see Grillner et al., 2008). These spinal networks are in turn activated by brainstem reticulospinal (RS) neurons, which are controlled by locomotor centers such as the mesencephalic locomotor region (MLR) (Shik et al., 1966; for review, see Jordan, 1998; Ryczko and Dubuc, 2013). The MLR has been shown to initiate and control locomotion in all vertebrate species tested (e.g., cat: Shik et al., 1966; rat: Skinner and Garcia-Rill, 1984; mouse: Lee et al., 2014; salamander: Cabelguen et al., 2003; birds: Sholomenko et al., 1991; and lamprey: Sirota et al., 2000). Located at the border between the midbrain and hindbrain, it initiates locomotion when stimulated electrically, pharmacologically, or optogenetically (Shik et al., 1966; Garcia-Rill et al., 1985; Lee et al., 2014; Roseberry et al., 2016; Caggiano et al., 2018; Josset et al., 2018). There is still a controversy relative to the different motor behaviors that can be elicited 
by MLR stimulation. In mammals, the MLR occupies a large area and stimulation of its subregions elicits different locomotor behaviors that are associated with food seeking, defense, or exploration (Sinnamon, 1993).

The MLR projects to RS cells (Orlovskii, 1970; Steeves and Jordan, 1984; Le Ray et al., 2003; Ryczko et al., 2016), the activity of which is strongly correlated with motor behavior (Drew et al., 1986; Deliagina et al., 2000; Bretzner and Brownstone, 2013; Kimura et al., 2013; Thiele et al., 2014). We have recently examined discharge patterns of RS cells during MLR-induced locomotion in the lamprey, a basal vertebrate (Juvin et al., 2016). Three activity patterns were identified and related to the locomotor output: one group of RS cells discharged transiently at the beginning of a locomotor episode, a second group fired action potentials throughout a whole locomotor bout, and a third group responded with a burst of action potentials at the beginning and another burst at the end of a locomotor episode (termination burst). The activity pattern of the third cell group was particularly interesting because it had not been described before in vertebrates. We demonstrated that pharmacological activation of these cells halted ongoing swimming activity, whereas inactivation slowed down the termination process. Therefore, we named them stop cells. Recently, there has been growing research interest on the neural mechanisms involved in stopping locomotion. A group of glutamatergic RS cells that play a crucial role in halting locomotion has been identified in mice (Bouvier et al., 2015). Optogenetic activation of these neurons (V2a "stop neurons") terminates ongoing locomotion, whereas blocking their synaptic output increases mobility. In another study, activation of inhibitory glycinergic brainstem neurons has also been shown to stop locomotion in mice (Capelli et al., 2017). Although these mammalian brainstem neurons clearly stop locomotion, their pattern of discharge has not been recorded as done in lampreys.

In lampreys, one key question remaining concerns the mechanism that triggers the termination burst in stop cells. It was hypothesized that synaptic inputs rather than intrinsic properties were involved (Juvin et al., 2016). In the present study, we unexpectedly discovered that the MLR provides such a synaptic input and we show that MLR stimulation not only initiates locomotion, but also stops it. Experiments were performed in semi-intact preparations in which intracellular recordings of RS cells can be correlated to active swimming movements of the intact body. We found that, during MLR-induced swimming, a second MLR stimulation delivered at an intensity lower than that used to start locomotion stopped ongoing locomotion. Moreover, this low-intensity MLR stimulation elicited a termination burst in stop cells. We found direct projections from the MLR to the stop cell region and evidence of glutamatergic and, most likely, monosynaptic connectivity. Our findings reveal a new function of the MLR in terminating locomotion via activation of stop cells.

\section{Materials and Methods}

Ethics statement. All procedures conformed to the guidelines of the Canadian Council on Animal Care and were approved by the animal care and use committees of the Université de Montréal and Université du Québec à Montréal (Québec, Canada). Care was taken to minimize the number of animals used and their suffering. All experiments were performed in larval sea lampreys (Petromyzon marinus) collected in a river near Notre-Dame-de-Stanbridge (Rivière aux Brochets, Québec, Canada). The animals were kept in aerated water at $5^{\circ} \mathrm{C}$ and received every other week $\sim 2 \mathrm{mg}$ of yeast per animal.
Semi-intact and isolated brain preparations. Semi-intact preparations $(n=58)$ were used to simultaneously record RS cell activity and locomotor movements (Antri et al., 2009; Ryczko et al., 2013). For this purpose, the brain and rostral spinal cord segments were dissected free and the caudal part of the body was kept intact. Animals were deeply anesthetized with tricaine methanesulphonate (MS 222, 100 mg/L; SigmaAldrich) and transferred into cold, oxygenated Ringer's solution containing the following (in $\mathrm{mm}$ ): $\mathrm{NaCl} 130.0, \mathrm{KCl} 2.1, \mathrm{CaCl}_{2} 2.6, \mathrm{MgCl}_{2}$ 1.8, HEPES 4.0, dextrose 4.0, and $\mathrm{NaHCO}_{3} 1.0$, adjusted to a pH of 7.4. A transverse incision was made on the ventral side at the level of the last pair of gills. Skin and muscle tissue was removed from the rostral part of the body and around the head. The brain and the rostral spinal cord segments were exposed dorsally by removing the surrounding tissue, skin, muscles, and cranial cartilage. The choroid plexus over the mesencephalic and fourth ventricles was removed to gain access to RS cells and the MLR. Decerebration was achieved by a complete transverse section of the neuraxis rostral to the mesencephalon. A dorsal midsagittal transection was performed at the isthmus to provide easier access to the MLR. The animals were transferred into a recording chamber continuously perfused with cold, oxygenated Ringer's solution. One part of the chamber was shallow and designed to pin down the rostral part of the preparation onto the Sylgard (Dow-Corning) lining at the bottom to record the activity of the brainstem neurons. The other part of the chamber was deeper and allowed the intact body to swim freely (Fig. 1C). Animals were allowed to recover for at least $1 \mathrm{~h}$ before recording. For anatomical experiments, isolated brain preparations of larval lampreys were used $(n=$ 11). The dissection procedure was the same as that described above except a complete transverse cut was made at the level of the last gills to remove the body.

Electrophysiological recordings and stimulation. Intracellular recordings of RS cells were made using sharp microelectrodes (80-120 M $\Omega$ ), filled with $4 \mathrm{~m}$ potassium acetate. The signals were amplified, sampled at a rate of $10 \mathrm{kHz}$ (Axoclamp 2A; Molecular Devices), and acquired through a Digidata 1200 series interface coupled to Clampex 8.1 software (Molecular Devices). Intracellular signals were analyzed using Clampfit 10.4 (Molecular Devices) or Spike2 5.19 software (Cambridge Electronic Design; RRID:SCR_000903). The MLR was electrically stimulated on one side to elicit swimming movements of the intact body. Trains of $2 \mathrm{~ms}$ pulses (frequency of $5 \mathrm{~Hz}$ for $10 \mathrm{~s}$ ) were delivered through custom made glass-coated tungsten microelectrodes $(4-5 \mathrm{M} \Omega$ with $10 \mu \mathrm{m}$ tip exposure) using a Grass S88 stimulator (Astro Med). Stimulation intensities ranged from $0.5-15 \mu \mathrm{A}$, theoretically corresponding to a maximum current spread of $130-281 \mu \mathrm{m}$ around the stimulation electrode (Ranck, 1975). Stimulation trains were delivered to the MLR with at least a 3 min waiting period in between. The location of the stimulation site was based on previous anatomical and physiological studies in the lamprey MLR, where the giant RS cell I1 (Rovainen, 1967) served as an MLR landmark (Ryczko et al., 2013; Juvin et al., 2016).

In a series of experiments, synaptic connectivity was tested using a high-divalent cation Ringer's solution $\left(10.8 \mathrm{mM} \mathrm{Ca}^{2+} / 7.2 \mathrm{mM} \mathrm{Mg}^{2+} ; \mathrm{El}\right.$ Manira et al., 1997; Brocard and Dubuc, 2003). In these experiments, the recording chamber was split between the head and body using petroleum jelly (Vaseline) and the Ringer's solution in the head chamber was replaced by the high-divalent cation solution. After $30 \mathrm{~min}$ of exposure to the high-divalent cation solution, the MLR was stimulated with 2 electrical shocks (2 ms) applied at $25 \mathrm{~Hz}$.

Drug application. In a series of experiments, we performed local applications of drugs (all dissolved in Ringer's solution): D-glutamate (5 mM, Sigma-Aldrich); acetylcholine (1 mM, Sigma-Aldrich); a mixture of the glutamate antagonists 6-cyano-7-nitroquinoxaline-2.3-dione disodium (CNQX, 1.25 mm; Tocris Bioscience) and 2-amino-5-phosphonovaleric acid (AP5, $5 \mathrm{~mm}$; Sigma-Aldrich). Microinjections were performed as described in previous studies (Paggett et al., 2004; Jackson et al., 2007). A glass micropipette (diameter of opening 10-20 $\mu \mathrm{m}$ ) was inserted in the MLR or the caudal middle rhombemcephalic reticular nucleus (MRRN) and the solutions were pressure ejected (2-6 pulses of 20-30 ms at 3-4 psi) using a Picospritzer (General Valve). The solutions were colored with the inactive dye fast green for visual guidance of the ejected droplets (Ryczko et al., 2017). Control injections consisted of Ringer's solution alone. 
A

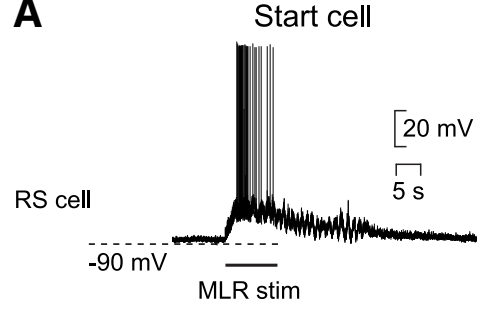

B

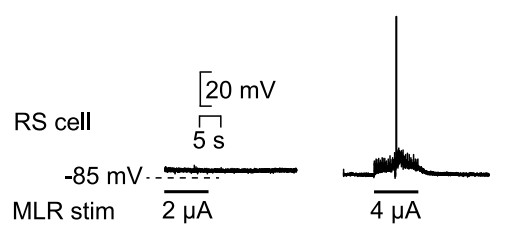

Maintain cell

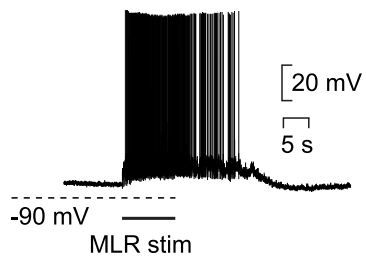

Stop cell

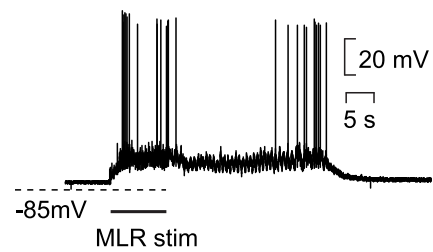

Stop cell
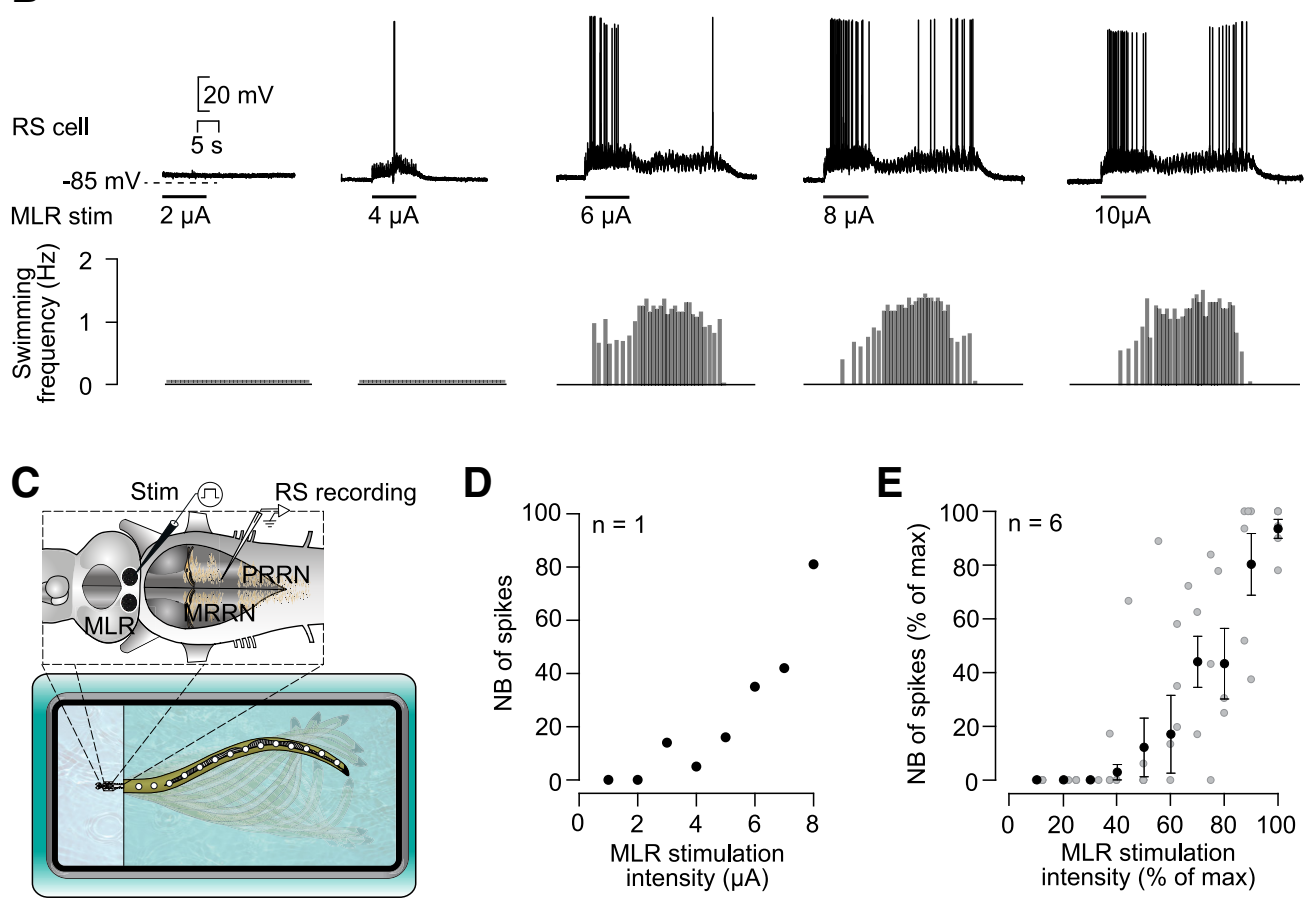

D

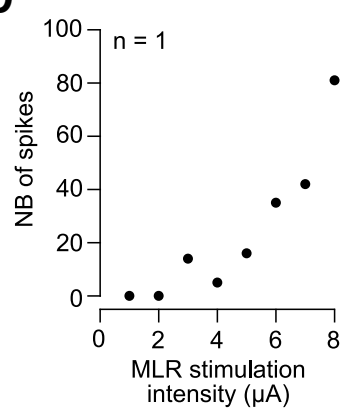

E

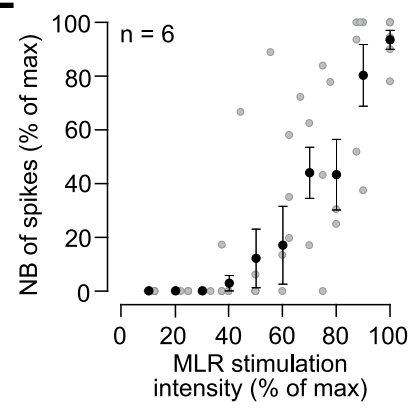

Figure 1. Response of stop cells to MLR stimulation of increasing intensity. A, Activity pattern of three populations of RS cells in response to MLR stimulation (adapted from Juvin et al., 2016): start cell (left), maintain cell (middle), and stop cell (right). $\boldsymbol{B}$, Concurrent intracellular recording of a stop cell (top) and swimming activity (bottom) in a semi-intact preparation in response to different MLR stimulation intensities $(2-10 \mu \mathrm{A})$. C, Schematic representation of the semi-intact preparation. The brainstem is illustrated with intracellular (RS cells) and stimulation electrodes (MLR). Swimming movements of the intact body are monitored with a video camera. $\boldsymbol{D}$, Relationship between the number of spikes in the termination burst and the intensity of the MLR stimulation $(n=$ 8 trials recorded in one stop cell). $\boldsymbol{E}$, Similar representation as in $\boldsymbol{D}$, but for six stop cells recorded in six preparations. Pooled data (black dots) were binned as a function of maximal stimulation intensity with a bin size of 10\% (52 individual trials; gray dots). The number of spikes and the stimulation intensities were normalized and are represented as a percentage of maximal values.

Kinematic analysis. A video camera (HDR-XR200; Sony) was placed $1 \mathrm{~m}$ above the recording chamber to record swimming movements of the intact body (sampling rate: 30 frame/s). Video recordings were analyzed using a custom-made script in MATLABR2009A (The MathWorks, RRID:SCR_001622; Brocard et al., 2010; Ryczko et al., 2013). Swimming movements were analyzed by digitally adding equally spaced markers offline along the midline of the body. The lateral displacement of the body curvature was then monitored for each frame. For this, the angle between the longitudinal axis of the nonmoving body parts (line along the body midline) and a straight line drawn between two successive markers located in the middle of the body was measured for the entire locomotor bout. The values are expressed in radians (rad).

Anatomical tracing. Anatomical experiments were performed to investigate the distribution of MLR cells projecting to different regions of the reticular formation. In these experiments, two injections were made on the same side of the reticular formation; fluorescein dextran amines were always used for the caudal injection and Texas red dextran amines for the rostral one. The first injection, the caudal one, consisted of a unilateral transverse section of the medial tegmentum using a microsurgical knife. The lesion was quickly filled with crystals of fluorescein dextran amines (3000 MW; Invitrogen) and left there to dissolve for $10 \mathrm{~min}$, allowing tracer uptake by the cut axons. After thorough rinsing of the injected area, the preparation was placed in cold oxygenated Ringer's solution to allow the tracer to retrogradely travel past the location of the more ros- tral, future second injection. After $4 \mathrm{~h}$, a second ipsilateral transverse section of the medial tegmentum was made and quickly filled with crystals of Texas red dextran amines (3000 MW; Invitrogen) and left there to dissolve for $10 \mathrm{~min}$. Care was taken so that tracer from the second injection did not spread to the first injection area. After thoroughly rinsing the second injection site, the preparation was again placed in cold, oxygenated Ringer's solution overnight. The next morning, it was transferred into a fixative solution ( $4 \%$ paraformaldehyde in $0.1 \mathrm{~m}$ phosphate buffer with $0.9 \% \mathrm{NaCl}, \mathrm{pH} 7.4$, and $\mathrm{PBS}$ ) for $24 \mathrm{~h}$, followed by an immersion in a sucrose solution ( $20 \%$ in phosphate buffer) for at least $24 \mathrm{~h}$. The brain was frozen and cross-sectioned $(25 \mu \mathrm{m})$ on a cryostat. The sections were placed on ColorFrost Plus microscope slides (Fisher Scientific) and rinsed with PBS and coverslipped using Vectashield mounting medium (with DAPI; Vector Laboratories). Labeled cell bodies in the MLR were observed under an E600 epifluorescent microscope equipped with a digital camera (DXM 1200; Nikon). The sections were photographed and levels were adjusted in Photoshop CS5 (Adobe Systems; RRID: SCR_014199) so that all fluorophores were clearly visible. The size of labeled MLR neurons was measured using a micrometric scale incorporated in the ocular of the fluorescence microscope. As described in previous studies, the diameter of the somata was measured along the longest axis as seen on the cross-sections (Le Ray et al., 2003; Gariépy et al., 2012).

Experimental design and statistical analysis. For the present study, sample size was not predetermined using a statistical method and was similar 

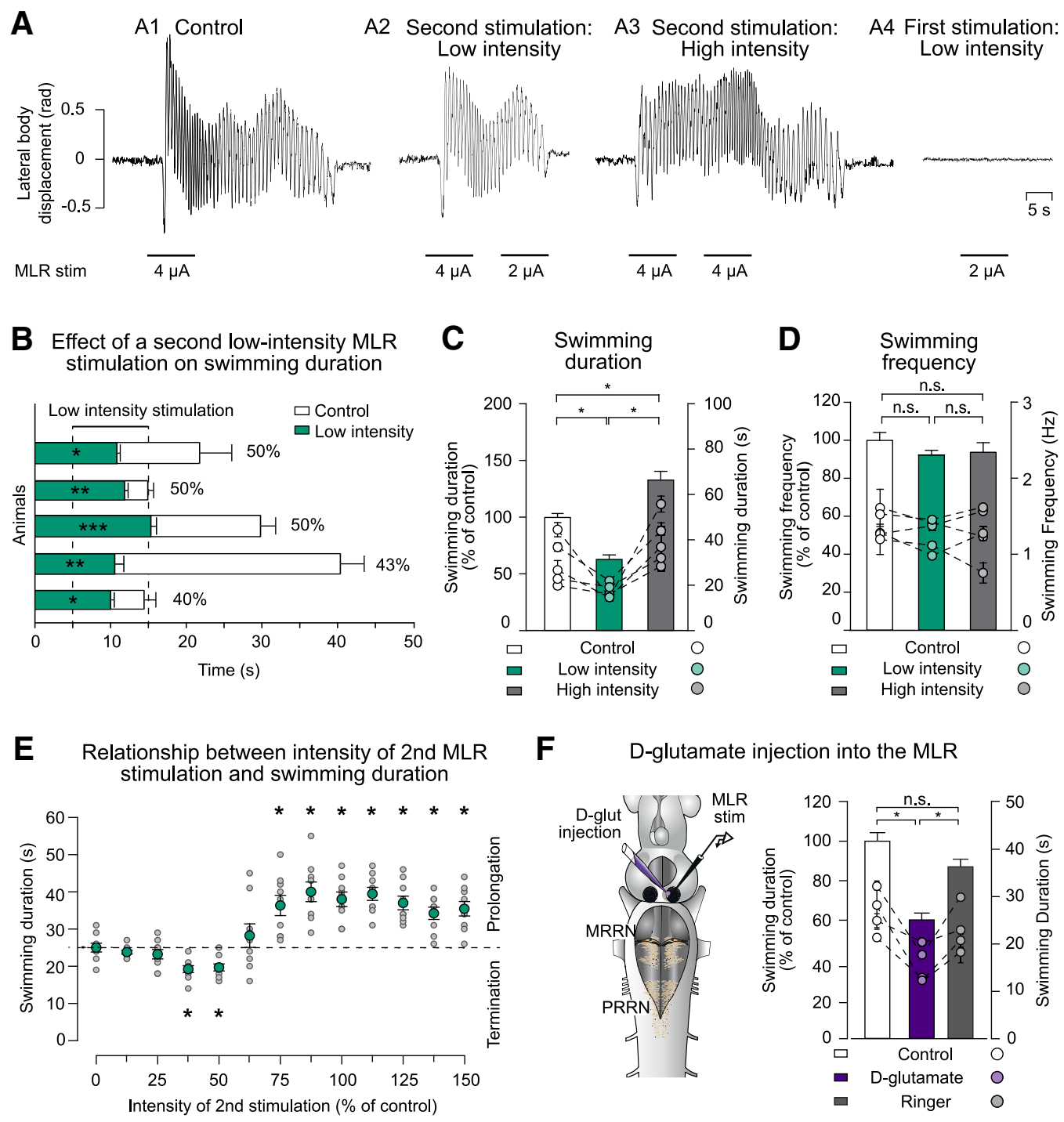

Figure 2. Effect of a second MLR stimulation on the swimming duration. $A$, Lateral displacement of the body (rad) is plotted for swimming bouts elicited by electrical MLR stimulation (control condition; $4 \mu \mathrm{A} ; \boldsymbol{A} \mathbf{1})$ when a second MLR stimulation of low intensity $(2 \mu \mathrm{A} ; \mathrm{A} \mathbf{2})$ or high intensity $(4 \mu \mathrm{A} ; \boldsymbol{A} \mathbf{3})$ was delivered $5 \mathrm{~s}$ after the end of the first MLR stimulation. MLR stimulation of low intensity did not trigger locomotion at rest ( $2 \mu \mathrm{A} ; \boldsymbol{A} 4)$ ). B Bar graphs illustrating the swimming duration (mean \pm SEM) in control conditions (white bars) and when the MLR was stimulated a second time at low intensity while the animal was swimming (green bars). Each line represents one animal ( $n=5$ trials for each condition). Time 0 represents the end of the first MLR stimulation. $C$, Histogram illustrating the average swimming duration under control condition (white bar) and when the MLR was stimulated a second time with low-intensity stimulation (green bar) or high-intensity stimulation (gray bar). Bars represent mean \pm SEM of pooled data that were normalized to control ( $n=25$ trials in 5 animals; left $y$-axis). Dots represent mean \pm SEM of raw data for each animal ( $n=5$ stimulations for each animal; right $y$-axis). $D$, Comparison of the average swimming frequency in three conditions: control (white bar), when a second MLR stimulation of low intensity is delivered (green bar), and when a second MLR stimulation of high intensity is delivered (gray bar). E, Swimming duration as a function of the intensity of the second MLR stimulation. For each trial, swimming was elicited by electrical MLR stimulation (100\%). Intensities of the second MLR stimulation were altered from 0\% to $150 \%$ of control in $12.5 \%$ steps. Gray dots represent swimming duration for each individual trial ( $n=9$ trials in 3 animals for each condition); green dots represent average duration (mean \pm SEM). The dotted horizontal line indicates the average swimming duration under control conditions when no second stimulation was delivered to the MLR. $\boldsymbol{F}$, Left, Schematic representation of the experimental setup when the second MLR stimulation was delivered by injection of small D-glutamate quantities ( $2-3$ pulses of $20 \mathrm{~ms}$; volume ejected: $0.36-0.55 \mathrm{pmol}$ ) or Ringer's solution. Right, Bar graph illustrating the average swimming duration in control conditions (white bar) and when D-glutamate (violet bar) or Ringer's solution (gray bar) was applied into the MLR during ongoing swimming. Data were normalized to the mean of control. Bars represent the mean \pm SEM of pooled data ( $n=20$ trials in 4 animals for each condition; left $y$-axis). Dots illustrate mean \pm SEM of raw data for each animal (right $y$-axis). ${ }^{*} p<0.05 ;{ }^{* *} p<$ $0.01 ; * * * 0.001 ;$ n.s. not statistically significant.

to the sample size used generally in the field. The sex of the individual larval animals was not taken into account. No blinding procedure or randomization was used in this study. Statistical analysis was performed with Sigma Plot 11.0 (Systat Software; RRID:SCR_010455) and R (R Core Team; http://www.r-project.org/; RRID:SCR_001905). Data in the text are represented as the mean \pm SEM. Comparisons between two groups were made using a paired $t$ test. In the cases in which normality and equal variance assumptions were not met, a Wilcoxon signed-rank test was applied to compare the two groups. When comparing more than two groups, a one-way ANOVA for repeated measures was used as para- metric and a Friedman ANOVA on ranks for repeated measures as nonparametric analyses. These analyses were followed by a StudentNewman-Keuls post hoc test as a pairwise multiple-comparisons procedure. To calculate correlations between variables, the Pearson product-moment correlation test was used. For all statistical analyses performed in this study, differences were considered statistically significant when $p \leq 0.05\left({ }^{*} p<0.05\right.$; $\left.{ }^{* *} p<0.01 ;{ }^{* *} p<0.001\right)$. Illustrations were made using Illustrator CS5 (Adobe Systems; RRID:SCR_010279).

Data availability. All relevant data are available from the authors upon request. 


\section{Results}

MLR stimulation stops

ongoing locomotion

In a previous study (Juvin et al., 2016), three types of discharge patterns were identified in RS cells in response to MLR stimulation: start, maintain, and stop patterns of discharge (Fig. 1A). In the present study, we focused on the RS cells that display a stop discharge pattern (stop cells) consisting of a burst at the beginning and one at the end of a locomotor bout (termination burst).

We then characterized the changes that occur in this termination burst as we increased the intensity of MLR stimulation. Stop cells were recorded intracellularly in semi-intact preparations, which allowed us to correlate the cellular discharge to the frequency of the swimming movements (Fig. 1C). Stimulation intensities below swimming threshold did not trigger the characteristic activation pattern of stop cells, including the termination burst (Fig. 1B). Only when the intensity of MLR stimulation was strong enough to elicit swimming did the stop cells produce the termination burst at the end of the locomotor bout. Interestingly, the higher the stimulation intensity was, the larger was the number of spikes in the termination bursts $\left(r=8.96 \times 10^{-1}, p=\right.$ $2.61 \times 10^{-3}$, Pearson product-moment correlation; $n=8$ samples in one animal; Fig. 1D). The same was true for pooled data recorded in several neurons $(r=$ $8.06 \times 10^{-1}, p=5.71 \times 10^{-13}$, Pearson product-moment correlation; $n=52$ samples in 6 animals; Fig. $1 E$ ). There was also a positive correlation between the number of spikes in the termination burst and the swimming frequency of the whole locomotor bout $\left(r=7.57 \times 10^{-1}, p=\right.$ $8.22 \times 10^{-11}$, Pearson product-moment correlation; $n=52$ samples in 6 animals).

The close relationship between the number of spikes in the termination burst and the intensity of MLR stimulation suggests that MLR inputs could trigger the termination burst. Therefore, the MLR would provide a signal that is responsible for stopping locomotion. To test this, we performed experiments in semi-intact preparations. Swimming activity was made to outlast the end of the MLR stimulation by using an intensity larger than needed to elicit swimming (Fig. 2A1). A second MLR stimulation was then applied during the swimming activity exceeding the duration of the stimulation. Applying a second stimulation at a low intensity ( $50 \%$ of control) but in the same MLR site stopped the swimming episode earlier
A

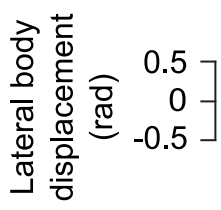

MLR stim

\section{Control}

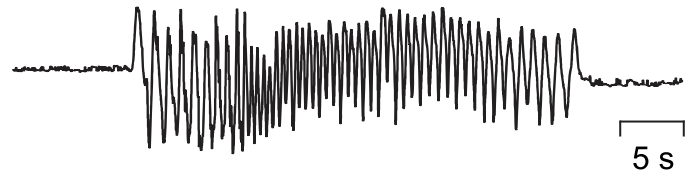

$100 \%$

\section{Low intensity stimulation after $10 \mathrm{~s}$}
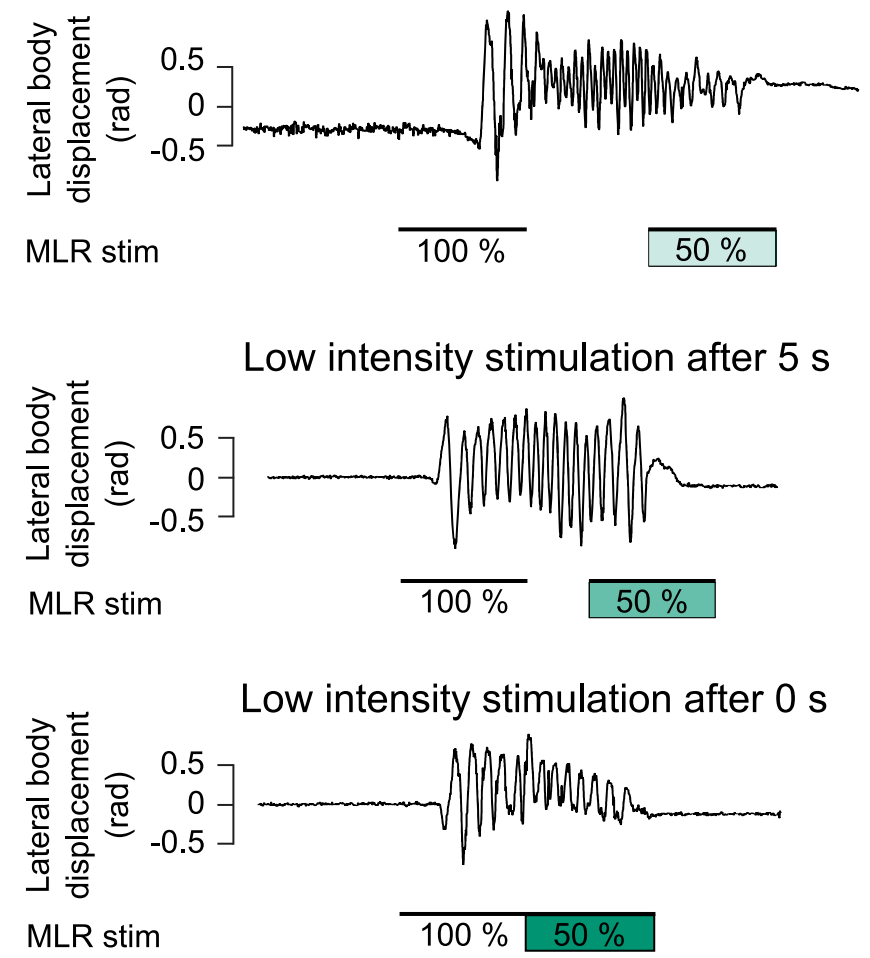

B

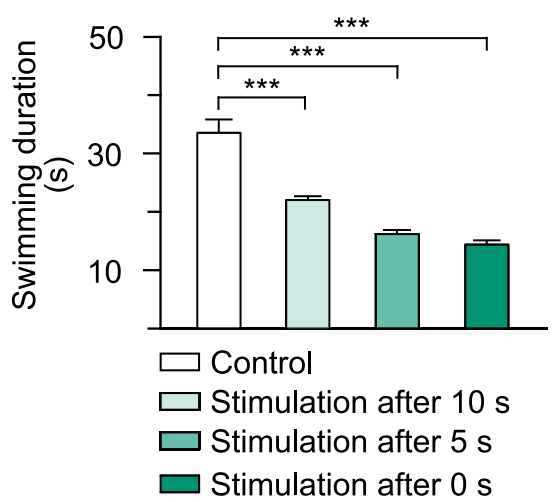

C

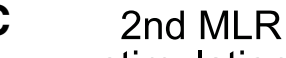
stimulation

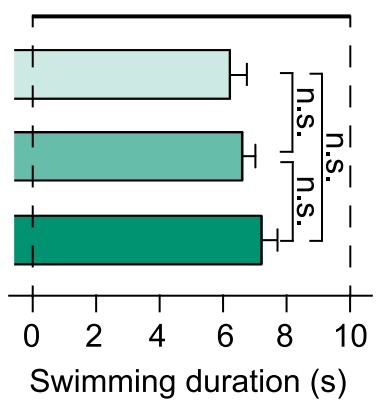

Figure 3. Effect of applying a second MLR stimulation at different times after a first MLR stimulation. $\boldsymbol{A}$, In a semi intact preparation, swimming was elicited with high-intensity MLR stimulation ( $100 \%$, control). A second MLR stimulation at a low intensity ( $50 \%$ of control) was delivered 10,5 , or 0 s after the first MLR stimulation had ended. $\boldsymbol{B}$, Histogram illustrating the average swimming duration in control condition ( $33.53 \pm 2.9 \mathrm{~s}$; white bar; $n=75$ trials), when a second MLR stimulation of low intensity was delivered $10 \mathrm{~s}(22.04 \pm 0.63 \mathrm{~s}), 5 \mathrm{~s}(16.17 \pm 0.74 \mathrm{~s})$, and $0 \mathrm{~s}(14.38 \pm 0.72 \mathrm{~s})$ after the end of the first MLR stimulation. Bars represent mean \pm SEM ( $n=25$ trials for each condition). C, Bar graph illustrating the time it takes to stop swimming after the onset of a second low-intensity MLR stimulation delivered 10,5 , or $0 \mathrm{~s}$ after the first MLR stimulation. ${ }^{* * *} p<0.001 ;$ n.s. not statistically different. 
A

A1
Sensory-evoked
locomotion

Control

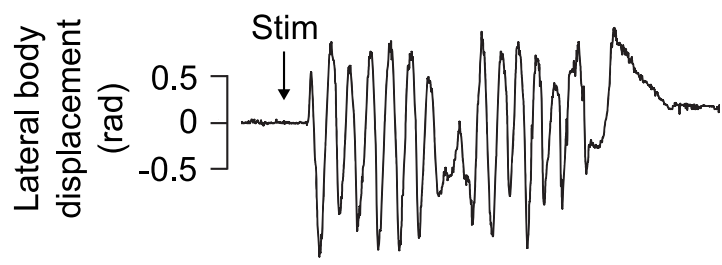

B

B1

\section{Spontaneous activity}

Control

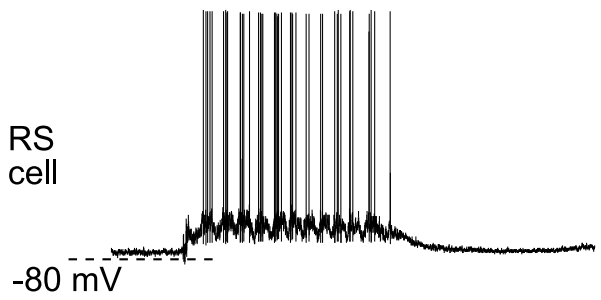

B2

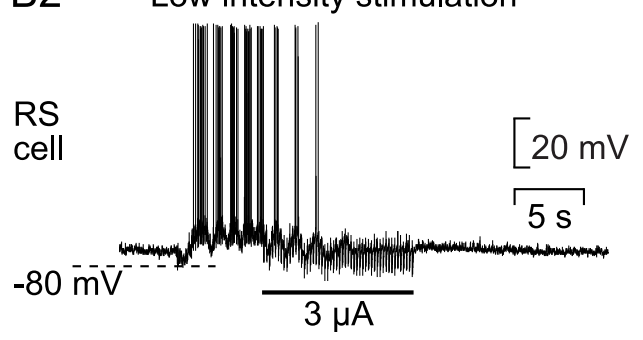

A2

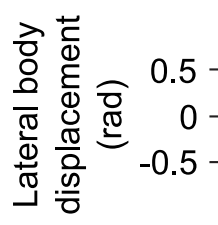

Low intensity stimulation<smiles>[SnH3]</smiles>

A3

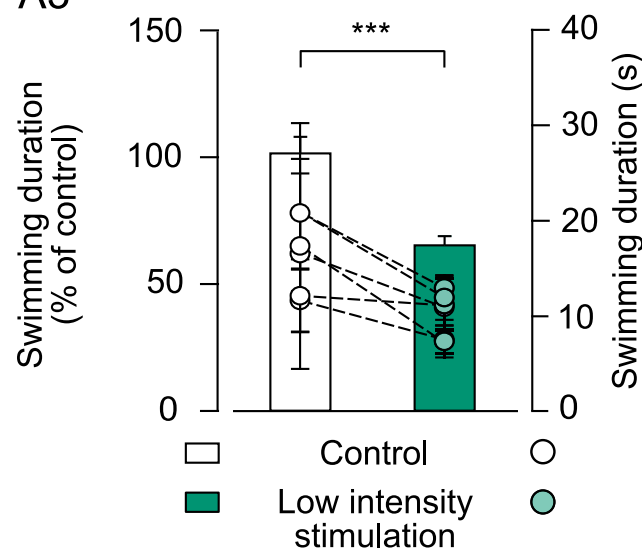

B3

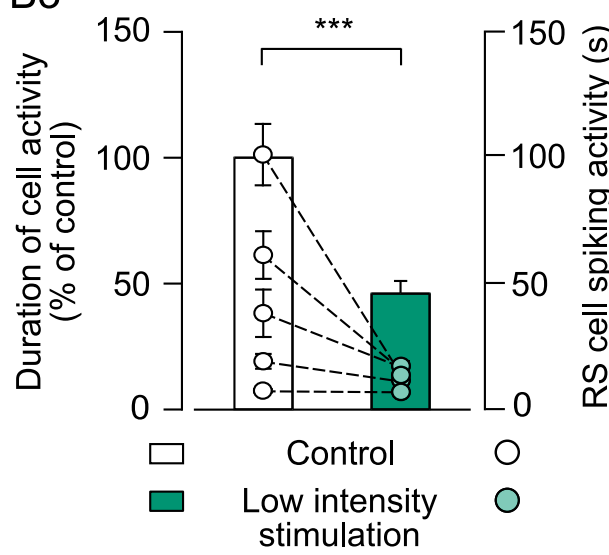

Figure 4. Effect of a low-intensity MLR stimulation on ongoing sensory-evoked or spontaneous swimming. A1, Kinematic analysis of the lateral body displacement (rad) during sensory-evoked swimming that was elicited by pinching the dorsal fin with forceps (Stim). A2, Representation of sensory-evoked swimming when a low-intensity stimulation was delivered to the MLR $5 \mathrm{~s}$ after the onset of swimming. A3, Histogram illustrating pooled data of average swimming duration ( $n=30$ trials in 6 animals) in control conditions (white bar) and when MLR was stimulated electrically of low intensity during sensory-evoked swimming (green bar). B1, Intracellular recording of a maintain cell that fires action potentials throughout the locomotor bout (monitored visually) used to analyze spontaneous locomotor activity. B2, Representation of cellular activity when MLR stimulation of low intensity was delivered during spontaneous swimming. B3, Histogram illustrating pooled data of duration of cellular activity in 5 animals ( $n=25$ events) in control conditions (white bar) and when the MLR was stimulated $5 \mathrm{~s}$ after swimming movements had started ( $\mathrm{green}$ bar). In both histograms, bars represent mean \pm SEM of the duration of swimming episodes or cellular activity normalized to average value of control (left $y$-axis). Dots represent average duration of swimming episodes or cellular discharge for each animal (mean \pm SEM; right $y$-axis). In all experiments, MLR stimulation intensities that would not induce locomotor activity in the resting preparation were used. ${ }^{* * *} p<0.001$.

than in the absence of a second stimulation (Fig. 2A2). It is noteworthy that such a low-intensity stimulation did not elicit locomotion at rest (Fig. 2A4). Interestingly, the locomotor bout was prolonged when the second MLR stimulation was made at the same intensity than the first one; that is, was sufficient to trigger locomotion at rest (Fig. 2A3). We then quantified the effects of a low-intensity MLR stimulation in five animals (Fig. 2B). On average, the intensity of the second MLR stimulation needed to significantly shorten the locomotor bout was $46.60 \%$ of control (ranging from $40 \%$ to $50 \%$ of the first stimulation). Overall, the duration of the locomotor activity outlasting the end of the MLR stimulation under control condition (i.e., without a second stimulation) was on average $24.29 \pm 2.28 \mathrm{~s}$ ( $n=25$ trials in 5 animals;
Fig. 2B, white boxes), with a range of 11.21-49.20 s. However, in the presence of a second low-intensity stimulation, the average duration of the locomotor activity outlasting the end of the first MLR stimulation was significantly decreased to $11.78 \pm 0.49 \mathrm{~s}$, ranging from $7.12-17.83 \mathrm{~s}\left(z=-4.37, p=5.96 \times 10^{-8}\right.$, Wilcoxon signed-rank test; Fig. $2 B$, green boxes). The animals stopped within $7.05 \pm 0.48 \mathrm{~s}$ after the beginning of the second stimulation. In the same animals, we compared the effects of a second MLR stimulation of low versus high intensity $(n=25$ trials for each condition; Fig. 2C). Here, the average duration of a whole swimming bout was significantly altered $\left(\chi_{(2)}^{2}=4.47 \times\right.$ $10^{1}, p<0.001$, Friedman ANOVA on ranks for repeated measures) to $62.95 \pm 3.96 \%$ of control when the MLR was stimulated 
A

A1
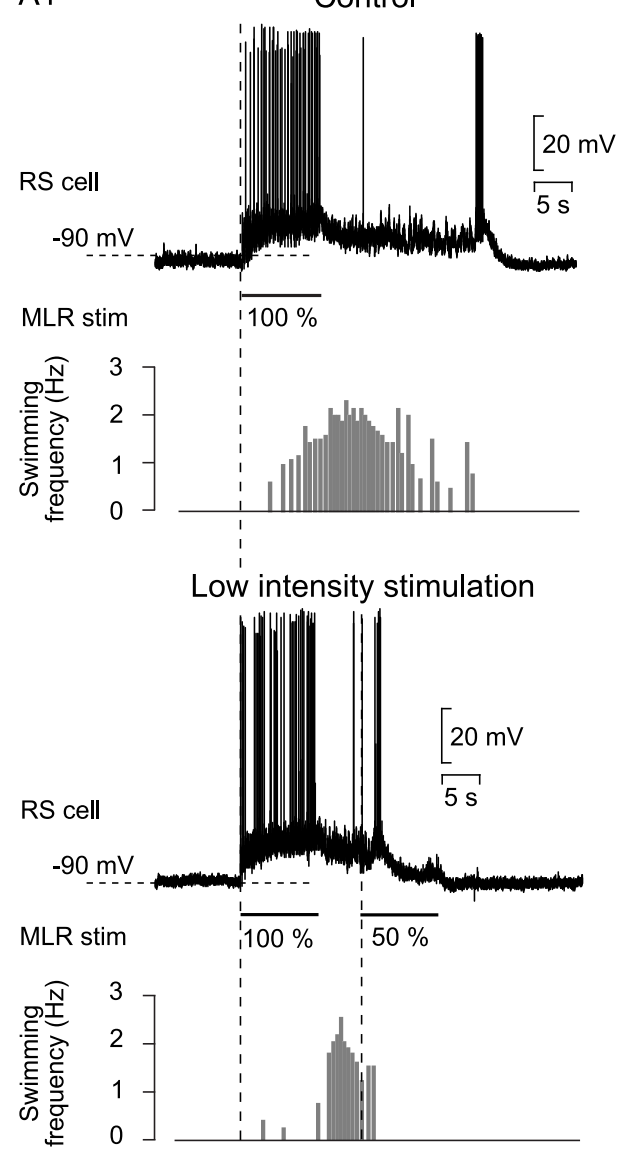

A2

Low intensity stimulation

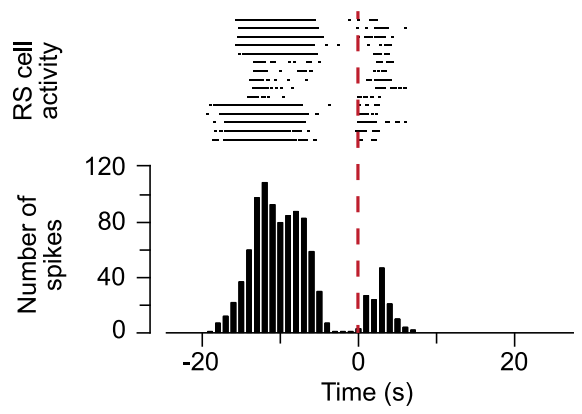

B

B1

Maintain cell

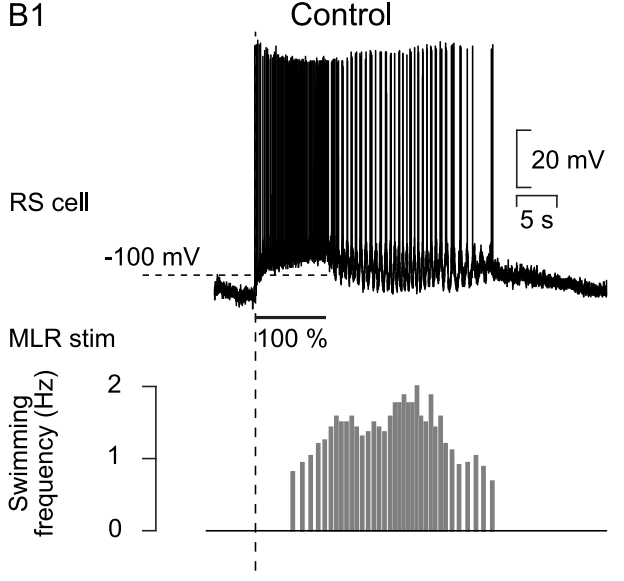

Low intensity stimulation

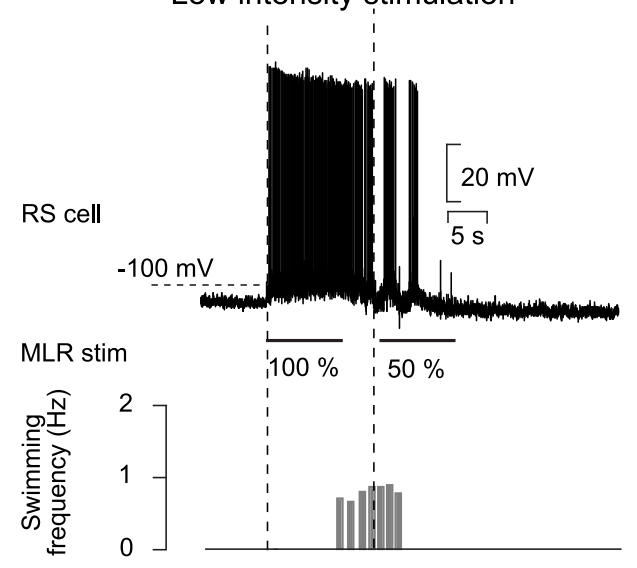

B2

Low intensity stimulation

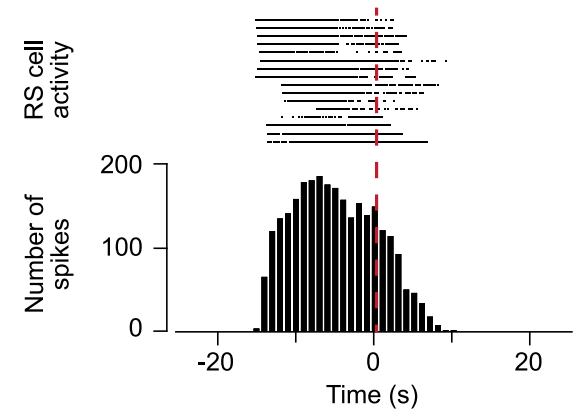

Figure 5. Relationship between termination burst and low-intensity MLR stimulation. $\boldsymbol{A}$, In semi-intact preparations, stop cells were recorded in control condition (top) and when a second MLR stimulation of low intensity (50\% of control) was delivered $5 \mathrm{~s}$ after the first MLR stimulation had ended (bottom). $\mathbf{A 2}$, Raster plot (top) and peristimulus histogram (bottom; bin size $=1 \mathrm{~s}$ ) illustrating the cellular activity of stop cells ( $n=15$ trials in 3 animals)aligned to the onset of the second MLR stimulation (dashed red line). B1, Representation of cellular activity of maintain cells that display spiking activity throughout the swimming episode (recorded in another animal). Maintain cells were recorded during MLR-induced swimming (control condition, top) and when the MLR was stimulated a second time with low intensity ( $50 \%$ of control; bottom). B2, Raster plot and peristimulus histogram representing spiking activity of maintain cells ( $n=16$ trials in 4 animals) aligned to the onset of MLR stimulation of low intensity (dashed line).

at a low intensity ( $p<0.5$, Student-Newman-Keuls test; Fig. $2 C$, green bar) and to $133.05 \pm 7.73 \%$ of control when the second MLR stimulation was delivered at a high intensity $(p<0.5$, Student-Newman-Keuls test; Fig. 2C, gray bar). Interestingly, the swimming frequency was not significantly altered by the second stimulation $\left(\chi_{(2)}^{2}=3.44, p=1.79 \times 10^{-1}\right.$, Friedman ANOVA on ranks for repeated measures; Fig. $2 D)$.

As shown in Figure $2 B$, the stimulation intensities of the second MLR simulation that significantly reduced the swimming duration varied from $40 \%$ to $50 \%$ of control. Another set of experiments was performed to define more precisely the range of intensities needed to shorten or prolong the swimming bouts (Fig. 2E). We first established the threshold intensity that was needed to elicit locomotion (1T) and then the control intensity was set to $2 \mathrm{~T}(100 \%)$. The intensity of the second stimulation was then varied from $0 \%$ to $150 \%$ of control (with $12.5 \%$ steps), which altered the duration of the locomotor bouts $\left(\chi_{(12)}^{2}=\right.$ $8.46 \times 10^{1}, p=5.34 \times 10^{-13}$, Friedman ANOVA on ranks for 


\section{A Ringer's solution}

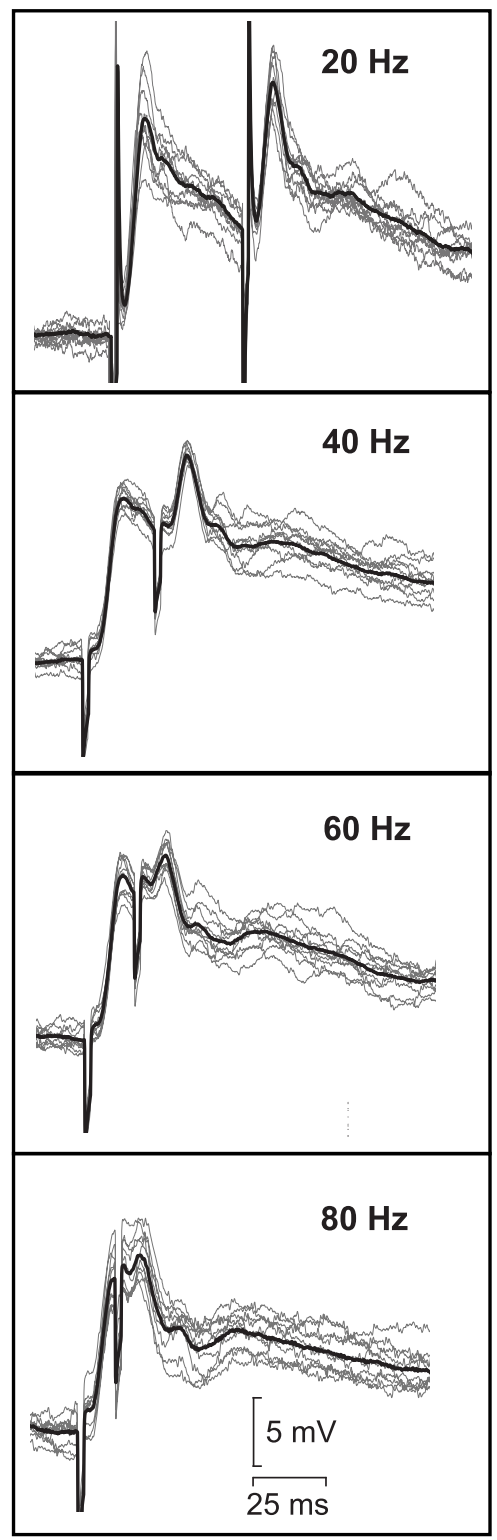

B Ringer's solution

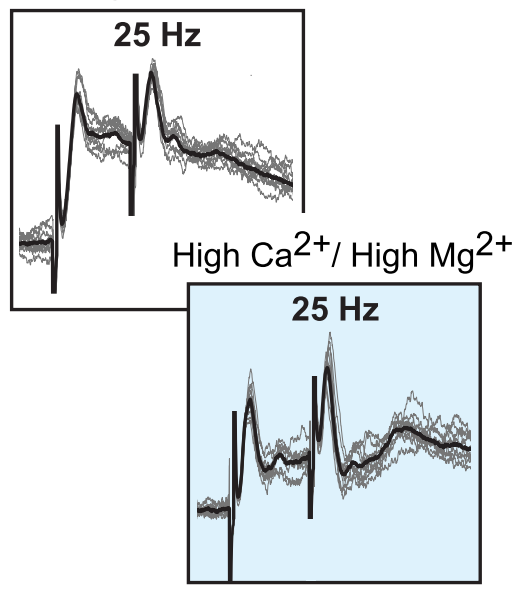

Figure 6. Synaptic inputs from the MLR to stop cells. $A$, Response of a stop cell to a pair of electrical shocks delivered to the MLR at different frequencies $(20,40,60$, and $80 \mathrm{~Hz})$. The black traces represent average cellular responses from one of four recorded stop cells ( $n=10$ sweeps; repeated measures; $n=9$ trials in 3 animals for each stimulation intensity). Under control conditions, when the MLR was stimulated only once at $100 \%$ intensity, the average duration of the locomotor bouts was $25.00 \pm 1.18 \mathrm{~s}$. When a second MLR stimulation was delivered during ongoing swimming, intensities $<37.5 \%$ of control had no significant effect on the swimming duration ( $p>0.5$; Student-Newman-Keuls test). Intensities between $37.5 \%$ and $50 \%$ produced a significant decrease $(19.22 \pm 0.92 \mathrm{~s}$ and $19.67 \pm 0.94 \mathrm{~s}$, respectively; $p<$ 0.5 ; Student-Newman-Keuls test), intensities between $50 \%$ and $75 \%$ produced no significant change in duration $(p>0.5$; Student-Newman-Keuls test), and intensities of $75 \%$ or higher increased the swimming duration significantly $(p<$ 0.5; Student-Newman-Keuls test).

To avoid activating fibers of passage in the MLR, electrical stimulation was replaced by pharmacological activation $(n=20$ trials in 4 animals; Fig. $2 F$ ). The MLR was first electrically stimulated to elicit locomotion and then D-glutamate $(5 \mathrm{~mm})$ was locally injected (2-3 pulses of $20 \mathrm{~ms}$ for each injection; volume ejected: $0.36-0.55 \mathrm{pmol})$ in the MLR as a second stimulation. In the same animals, the D-glutamate solution was then exchanged for Ringer's solution. Swimming duration was altered $\left(\chi_{(2)}^{2}=\right.$ $2.59 \times 10^{1}, p=2.38 \times 10^{-6}$, Friedman ANOVA on ranks for repeated measures) and injection of D-glutamate shortened the locomotor bouts significantly $(60.13 \pm 3.47 \%$ of control; $p<0.5$, Student-Newman-Keuls test; Fig. $2 F$, violet bar). Conversely, injecting Ringer's solution had no significant effect on swimming duration ( $87.01 \pm 3.88 \%$ of control, $p>0.5$; Student-NewmanKeuls test; Fig. $2 F$, gray bar).

To test whether there was a refractory period during which a second low-intensity MLR stimulation could not stop locomotion, the time interval between the end of the first stimulation and the beginning of the second stimulation was reduced in steps from $10 \mathrm{~s}, 5 \mathrm{~s}$, to $0 \mathrm{~s}$. In all cases, the second low-intensity stimulation shortened the locomotor bout compared with control condition (Fig. $3 A, B$ ). It was further observed that locomotion ended $6.27 \pm 0.48 \mathrm{~s}, 6.56 \pm 0.46 \mathrm{~s}$, and $7.15 \pm 0.52 \mathrm{~s}$ after the onset of the second stimulation for intervals of $10 \mathrm{~s}, 5 \mathrm{~s}$, and $0 \mathrm{~s}$, respectively $\left(F_{(2,48)}=9.83 \times 10^{-1} ; p=3.81 \times 10^{-1}\right.$, one-way ANOVA for repeated measures, $n=25$ trials in 5 animals; Fig. $3 C)$.

In semi-intact preparations, swimming could be elicited by sensory stimulation or it could occur spontaneously (Di Prisco et al., 1997, 2000). Both sensory-evoked and spontaneous locomotor episodes could be stopped by low-intensity MLR stimulation (Fig. 4A, B). After pinching the dorsal fin (Stim; Fig. 4A1), longlasting swimming movements were elicited in resting animals ( $n=30$ trials in 6 animals). Low-intensity MLR stimulation applied during the sensory-evoked swimming activity stopped the locomotor bout significantly earlier compared with the control condition $(64.31 \pm 3.57 \%$ of control; $z=-3.96, p=1.60 \times$ $10^{-5}$, Wilcoxon signed-rank test; Fig. $\left.4 A 2, A 3\right)$. Due to their rarity, spontaneous swimming bouts were not recorded kinematically, but were monitored through intracellular recordings of RS cells ( $n=25$ trials in 5 animals; Fig. $4 B 1$ ). The spontaneous

$\leftarrow$

gray traces). $\boldsymbol{B}$, Double electrical shocks were delivered to the MLR at $25 \mathrm{~Hz}$ while a stop cell was recorded intracellularly. To reduce the likelihood of polysynaptic transmission, a high-divalent cation Ringer's solution was applied in the recording chamber (right, blue box) (El Manira et al., 1997; Brocard and Dubuc, 2003). Black traces represent average cellular responses from one of three recorded stop cells ( $n=10$ sweeps; gray traces). 


\section{A1}
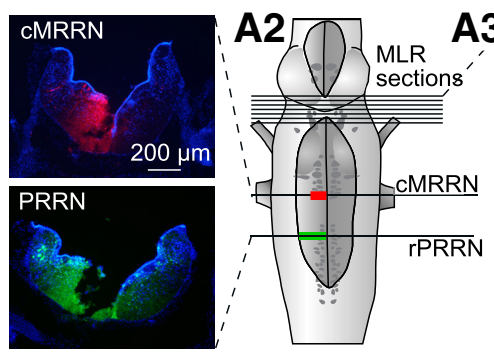

A3

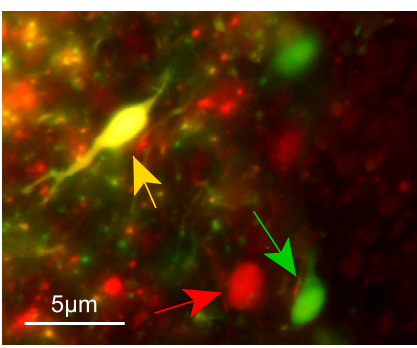

- Cells projecting to caudal MRRN

- Cells projecting to rostral PRRN

Double labelled cells

I1 Cell

B

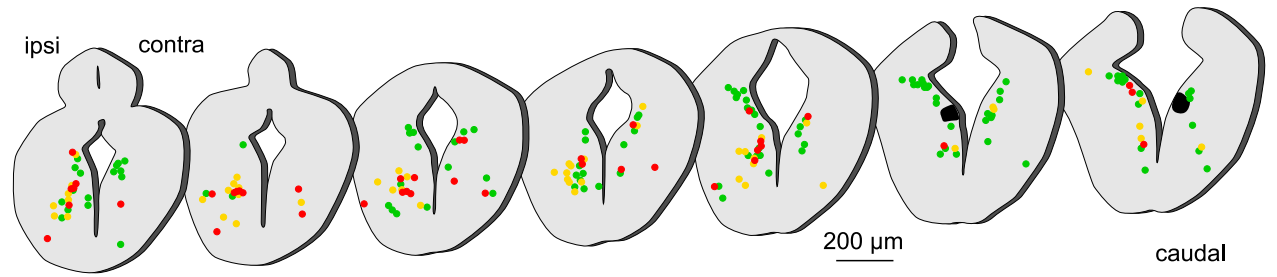

rostral
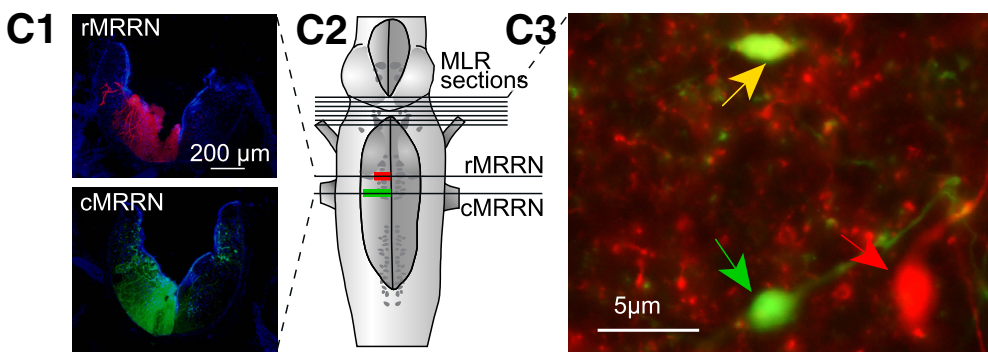

- Cells projecting to rostral MRRN

- Cells projecting to caudal MRRN

- Double labelled cells

I1 Cell

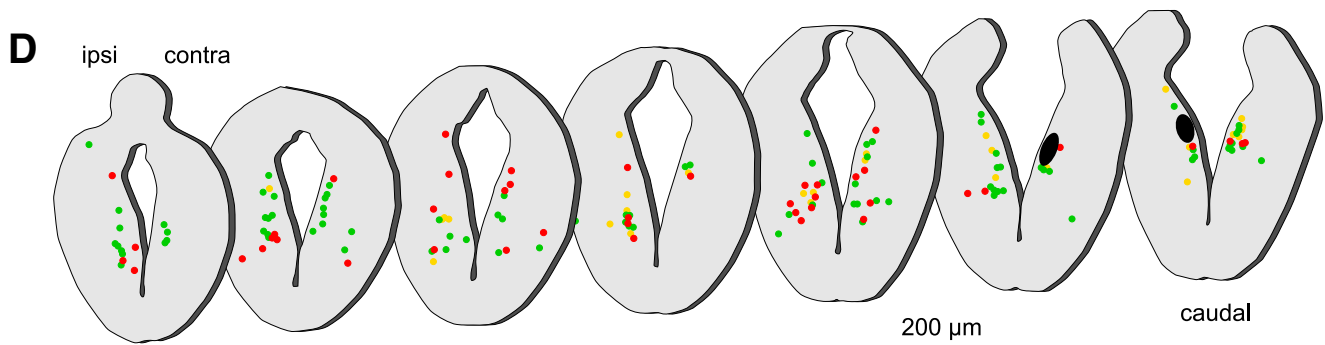

rostral

Figure 7. Distribution of MLR cells projecting to different areas of the reticular formation. $\boldsymbol{A} 1$, Tracer injections were made at two rostrocaudal levels of the reticular formation, one in the rostral pole of the PRRN (rPRRN) and the other one slightly more rostral, where stop cells are located (caudal MRRN; cMRRN). The extent of each injection is illustrated on photomicrographs of cross-sections. A2, Illustration of the injection sites on a schematic representation of the brainstem. A3, High-magnification photomicrograph (red and green filter sets images were merged) of a cross-section at the isthmic level illustrating neurons that were retrogradely labeled in the MLR, some with one of the tracers (red and green arrow) and others with both tracers (yellow arrow). MLR cells that sent projections to the stop-cell-rich area (caudal MRRN) were labeled with the red tracer. Neurons that sent projections passed the caudal MRRN were double labeled or labeled in green. $\boldsymbol{B}$, Schematic cross-sections through the rostrocaudal extent of the MLR showing neurons labeled on both sides. Red dots represent single-labeled MLR cells that project to the caudal MRRN but do not reach the rostral pole of the PRRN. Green and yellow dots represent MLR cells projecting at least as far as the rostral pole of the PRRN past the stop-cell-rich area. The giant RS cell I1 that is used as a landmark to identify the caudal extent of the MLR is represented in black. C1, Tracer injections were made at two rostrocaudal levels of the reticular formation, one in the stop-cell-rich area (cMRRN) and the other slightly more rostral in the maintain cell area ( $r M R R N)$. The extent of each injection is illustrated on photomicrographs of cross-sections. $\mathbf{C}$,Schematic representation of the brainstem with the two injection sites. C3, High-magnification photomicrograph (red and green filter sets images were merged) of a cross-section at the isthmic level illustrates neurons that were retrogradely labeled in the MLR, some with one of the tracers (red and green arrow) and others with both tracers (yellow arrow). The MLR neurons that sent projections to the rostral MRRN, where maintain cells are predominantly located, were only labeled with the red tracer, whereas all neurons that sent projections further caudally to the caudal MRRN were double labeled or labeled only in green. $D$, Schematic cross-sections through the rostrocaudal extent of the MLR showing neurons labeled on both sides. Red dots represent single-labeled MLR neurons that project to the maintain cell area but do not reach the stop cell area in the caudal MRRN. Green and yellow dots represent MLR neurons projecting at least as far as the caudal MRRN past the maintain-cell-rich area of the rostral MRRN.

locomotor episodes were also stopped earlier by a MLR stimulation of low intensity $\left(46.02 \pm 5.03 \%\right.$ of control; $t_{(24)}=9.00 ; p=$ $7.92 \times 10^{-9}$, paired $t$ test; Fig. 4B2,B3). In both experiments, MLR stimulation intensities below swimming threshold were chosen as low-intensity MLR stimulation.
Termination burst in stop cells is time linked to the second MLR stimulation

Stop cells display a termination burst associated with the end of swimming regardless of the way it is initiated (MLR stimulation, cutaneous stimulation, spontaneous; Juvin et al., 2016). In the 

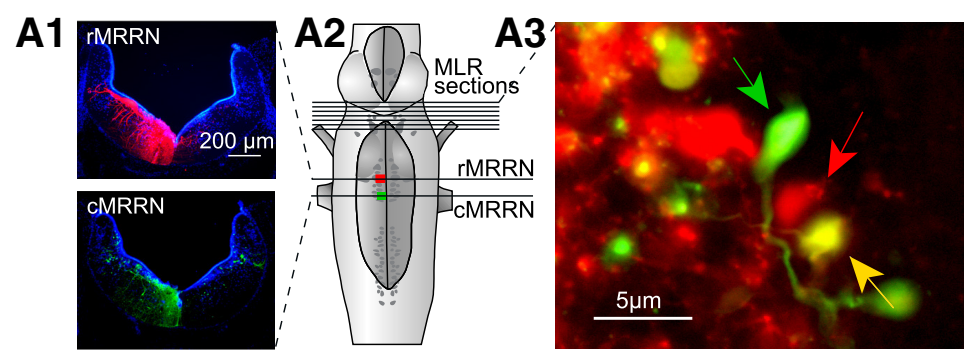

- Cells projecting to rostral MRRN

- Cells projecting to caudal MRRN

Double labelled cells

B

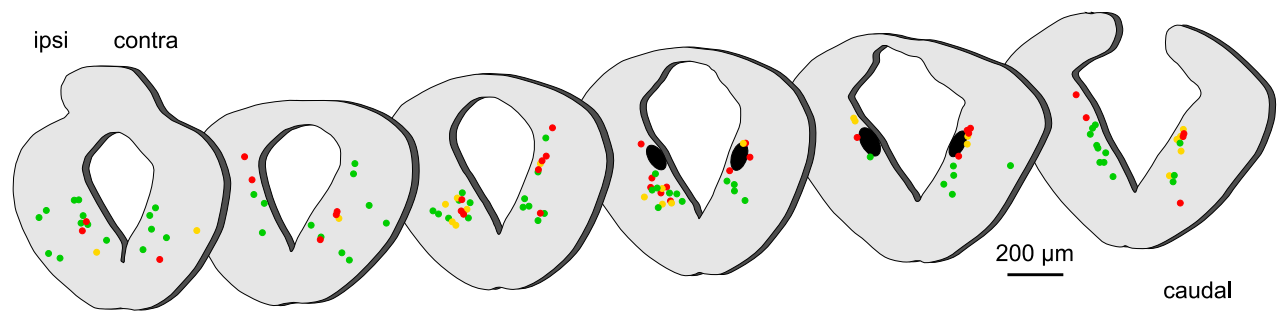

rostral

Figure 8. Distribution of MLR cells projecting to the maintain cell area or/and to the stop cell area. $\mathbf{A 1}$, Localized tracer injections were made in the stop cell area (caudal MRRN; CMRRN) and in the maintain cell area (rostral MRRN, rMRRN). A2, Schematic representation of the brainstem illustrating the two injections that were smaller and more medial compared with the injections made in the previous experiments (Fig. $7 C, D)$. A3, High-magnification photomicrograph (red and green filter sets images were merged) of a cross-section at the isthmic level illustrates neurons that were retrogradely labeled in the MLR, some with one of the tracers (red and green arrow) and others with both tracers (yellow arrow). $\boldsymbol{B}$, Representations of schematic cross-sections through the rostrocaudal extent of the MLR showing neurons labeled on both sides. Red dots represent single-labeled MLR neurons that project to the maintain cell area in the rostral MRRN. Green and yellow dots represent MLR neurons projecting at least as far as to the stop cell area in the caudal MRRN.

case of MLR-induced swimming, we investigated whether the burst occurs time linked with a second MLR stimulation at a low intensity (Fig. 5A1). The cellular activity of several stop cells was transformed into a raster display and the trials were temporally aligned on the onset of the second MLR stimulation ( $n=15$ trials in 3 animals; Fig. 5A2). This second MLR stimulation of low intensity stopped locomotion significantly earlier compared with the control condition $\left(69.90 \pm 7.26 \%\right.$ from control; $t_{(14)}=3.41$; $p=4.23 \times 10^{-3}$, paired $t$ test). Both the raster plot and the peristimulus histogram showed an increase in spiking activity right after the onset of the second MLR stimulation (Fig. 5A2). This indicates that the termination burst is systematically time linked to the onset of the second MLR stimulation. Maintain cells ( $n=16$ trials in 4 animals; Fig. $5 B$ ) were also recorded while locomotion was stopped by MLR stimulation (decrease of swimming duration: $77.35 \pm 4.60 \%$ of control; $t_{(15)}=3.28 ; p=5.00 \times$ $10^{-3}$, paired $t$ test). In contrast to stop cells, the maintain cells did not display a termination burs regardless of whether a second MLR stimulation was applied (Fig. 5B1, top and bottom). When a second MLR stimulation of low intensity was applied, it produced a sustained spiking activity until the cell repolarized at the end of the swimming bout, as illustrated in the raster display and the peristimulus histogram (Fig. 5B2).

\section{Connectivity between the MLR and stop cells}

We then examined the connectivity between the MLR and stop cells. Stop cells were intracellularly recorded to monitor their response to electrical shocks applied to the MLR (Fig. 6). The MLR stimulation intensity was set at $50 \%$ of the intensity needed to trigger a locomotor bout. Under these conditions, double shocks delivered at 20,40,60, and $80 \mathrm{~Hz}$ elicited short-latency EPSPs ( 2.8 to $3.2 \mathrm{~ms} ; n=4$; Fig. $6 A$ ). As the time interval between shocks was shortened, the latency of the EPSPs remained unchanged. Next, a high concentration of divalent cations was added to the Ringer's solution to reduce the likelihood of polysynaptic transmission (El Manira et al., 1997; Brocard and Du- buc, 2003). Double shocks were delivered to the MLR at $25 \mathrm{~Hz}$ and in the recorded stop cells $(n=3)$ the EPSPs were not changed, suggesting that at least part of the connection between the MLR and stop cells is monosynaptic (Fig. $6 B$ ).

Anatomical experiments $(n=11)$ were then performed to examine MLR projections to different regions of the reticular formation (Fig. 7). In each animal, two different injections (two tracers) were made on the same side of the reticular formation. In all experiments, the most caudal injection was made using a green tracer (fluorescein dextran amines) and the second one using the red tracer (Texas red dextran amines). The rostral injection was made $4 \mathrm{~h}$ after the caudal one to allow the tracer used for the caudal injection to travel past the rostral injection site. The caudal injection was made larger than the rostral one. Because of this, MLR neurons with axons projecting to the rostral site were labeled only in red, whereas the MLR neurons that project to the caudal site were labeled by the two tracers (double-labeled) or only in green if they bifurcate from the midline. Using this double-labeling approach, we examined populations of MLR cells that projected to three different regions of the reticular formation (the stop cell area, the maintain cell area, and the rostral posterior rhombencephalic reticular nucleus). The experiments were performed in two groups of animals. In the first group, the rostral injection was made in the stop cell area (caudal MRRN), whereas the caudal one was made in the rostral pole of the posterior rhombencephalic reticular nucleus (rostral PRRN) (Fig. $7 A 1-A 3 ; n=4$ animals). We found that the retrogradely labeled cells projecting to the stop cell area (Fig. $7 \mathrm{~B}$, red dots) were widely distributed on both sides of the MLR and were intermingled with the cells projecting more caudally to the rostral pole of the PRRN. In a second group of animals $(n=4)$, the rostral injection was made in the maintain cell area (rostral MRRN) and the caudal one in the stop cell area (caudal MRRN) (Fig. 7C1-C3). As described for the first group of animals, retrogradely labeled cells with projections to the maintain cell area (Fig. $7 D$, red dots) were widely distributed on both sides of the MLR and they were inter- 
mingled with the cells projecting more caudally in the stop cell area. When comparing retrogradely labeled MLR cells from the caudal MRRN (Fig. 7B) and the rostral MRRN (Fig. 7D), we found no difference in the diameter of the cell bodies. MLR cells projecting to the caudal MRRN (Fig. $7 B$ ) had an average diameter of $8.83 \pm 0.23 \mu \mathrm{m}$ and those projecting to the rostral MRRN (Fig. $7 D)$ had an average diameter of $8.93 \pm 0.18 \mu \mathrm{m}\left(U=2.75 \times 10^{3}\right.$, $n_{1}=76, n_{2}=77 ; p=0.52$; Mann-Whitney rank-sum test). Moreover, we found no apparent clustering of these two groups of cells. Because these comparisons were not made in the same animals, another series of experiments was performed with the injections made in the same animal $(n=3$; Fig. 8A1-A3). Both injections were also made smaller with one made in the maintain cell area (rostral MRRN) and the other in the stop cell area (caudal MRRN) (Fig. 8A2). Results from these experiments were very similar to those obtained previously. MLR cells projecting to the two regions were intermingled (cf. green and yellow dots with red dots in Fig. $8 B$ ). Together, these observations suggest that there is no clear anatomical clustering of MLR cells projecting to different areas of the reticular formation.

\section{Neurotransmitters involved in the stop signal from the MLR}

Pharmacological experiments were performed to determine the neurotransmitters responsible for activating RS stop cells by the MLR (Fig. 9). In the lamprey, it has been shown that MLR inputs to RS cells are glutamatergic and cholinergic (Le Ray et al., 2003; Brocard et al., 2010). In the present experiments, locomotion was elicited using electrical MLR stimulation and, during the ongoing locomotor bout, D-glutamate (Fig. 9B) or acetylcholine (Fig. 9C) was bilaterally injected into the stop cell region (Fig. $9 A$ ). As described previously (Juvin et al., 2016), injections of D-glutamate (5 mm; 3-6 pulses of $30 \mathrm{~ms}$ for each injection) significantly shortened the duration of the locomotor bout $(52.32 \pm$ $4.12 \%$ of control condition; $F_{(2,58)}=6.66 \times 10^{1} ; p=9.57 \times$ $10^{-16}$, one-way ANOVA for repeated measures; $p<0.001$, Student-Newman-Keuls test; $n=30$ trials in 6 animals). Conversely, bilateral injections of acetylcholine into the stop cell region ( $1 \mathrm{~mm}, 3-6$ pulses of $30 \mathrm{~ms}$ for each injection) had no effects on the duration of the swimming bout $(100.42 \pm 3.19 \%$ of control; $F_{(2,58)}=9.13 \times 10^{-2} ; p=9.13 \times 10^{-1}$, one-way ANOVA for repeated measures, $n=30$ trials in 6 animals).

The previous results strongly suggest that glutamatergic inputs from the MLR are responsible for the stop signal and not the cholinergic inputs. To test this further, another set of experiments was performed in which glutamatergic receptors were blocked in the stop cell region (Fig. 10A). First, locomotion was induced by MLR stimulation (Fig. 10B1) and then a second MLR stimulation of low intensity was applied to reduce the duration of the locomotor bout (Fig. 10B2). A mixture of the glutamate receptor antagonists CNQX (1.25 mM) and AP5 (5 mM) was then injected bilaterally over the stop cell region after locomotion was induced by electrical stimulation of the MLR (Fig. 10B3). When a second MLR stimulation of low intensity was delivered under CNQX and AP5, the duration of the swimming bout was no longer significantly different from the control condition (oneway ANOVA for repeated measures, $n=25$ trials in 5 animals $\left.F_{(2,48)}=4.98 \times 10^{1} ; p=1.99 \times 10^{-12}\right)$. The initial reduction of $60.74 \pm 3.47 \%$ of control ( $p>0.001$, Student-Newman-Keuls test; Fig. $10 B 2$ and $C$, green bar) was reversed to $109.92 \pm 4.60 \%$ of control $\left(p=6.30 \times 10^{-2}\right.$; Student-Newman-Keuls test; Fig. $10 B 3$ and $C$, orange bar). These results indicate that glutamatergic projections are responsible for transmitting the stop signal to the stop cells.

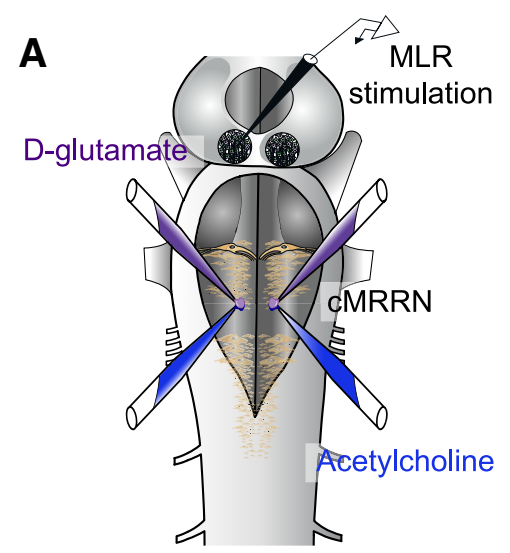

B D-glutamate

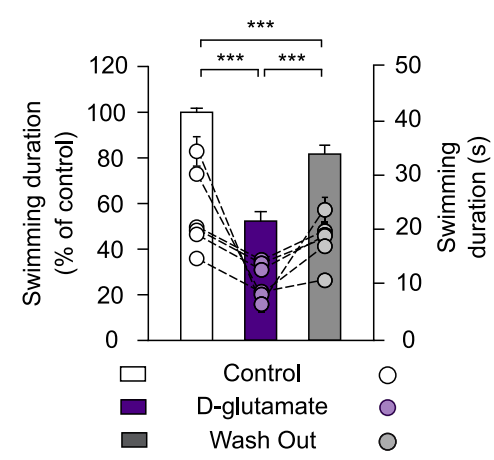

C Acetylcholine

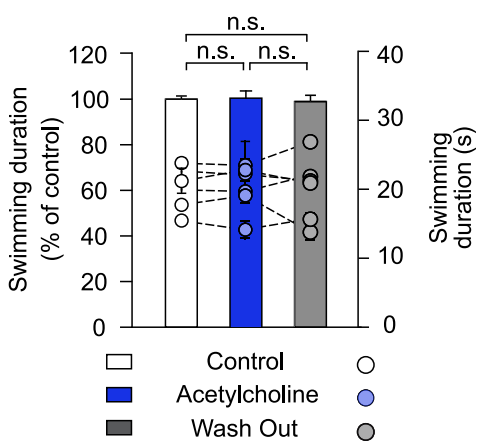

Figure 9. Effects of injecting glutamatergic and cholinergic agonists into the stop cell region. $A$, In a semi-intact preparation, bilateral injections of $\mathrm{D}$-glutamate or acetylcholine were made in the stop cell region (caudal MRRN) and electrical MLR stimulation was used to induce locomotion. Injection and stimulation sites are illustrated in the schematic representation of the brainstem. $\boldsymbol{B}, \mathrm{D}$-Glutamate was bilaterally injected into the stop cell region during MLR-induced swimming. Compared with control conditions (white bar), swimming duration was significantly shortened by a local D-glutamate injection (violet bar) and this effect was reduced after a washout period of $1 \mathrm{~h}$ (gray bar). C, Acetylcholine was bilaterally injected into the stop cell region during MLR-induced swimming. The duration of swimming was not significantly altered compared with control conditions (white bar), when acetylcholine was locally injected in the caudal MRRN (blue bar), or after a washout period of $1 \mathrm{~h}$ (gray bar). Data were normalized to the mean of control. In both experiments, bars represent the mean \pm SEM of pooled data $(n=30$ trials in 6 animals for each condition; left $y$-axis). Dots illustrate mean \pm SEM of raw data for each animal (right $y$-axis). ${ }^{* * *} p<0.001 ;$ n.s. not statistically significant.

\section{Discussion}

In the present study, we uncovered a neural substrate that controls the termination of locomotion. It was previously shown in different vertebrate species that the MLR activates RS cells to start and maintain locomotion (Orlovskiü, 1970; Steeves and Jordan, 
A

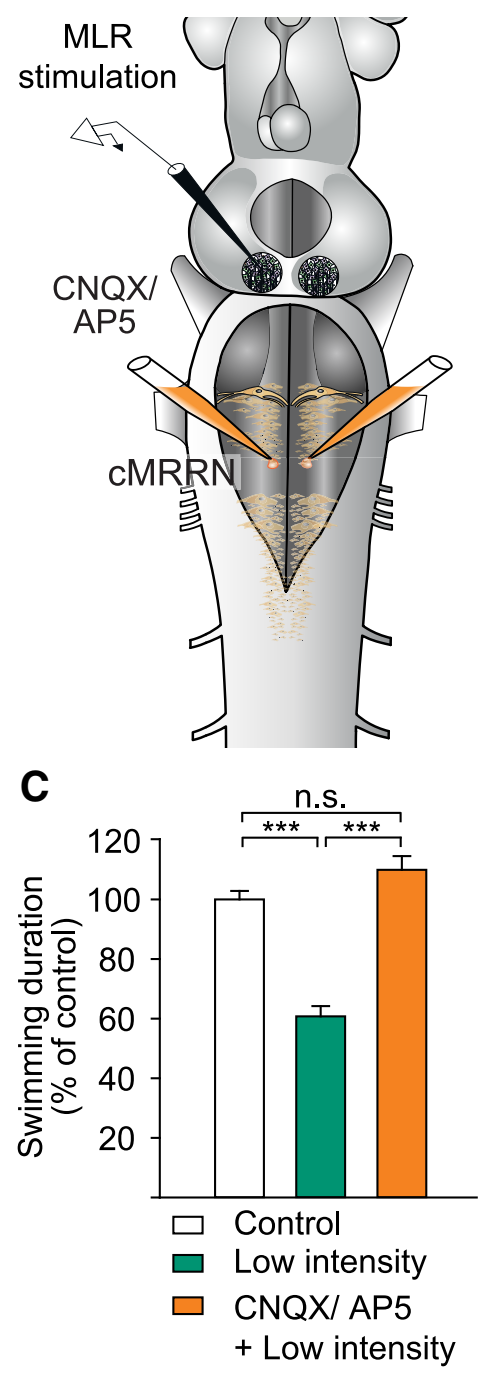

B1
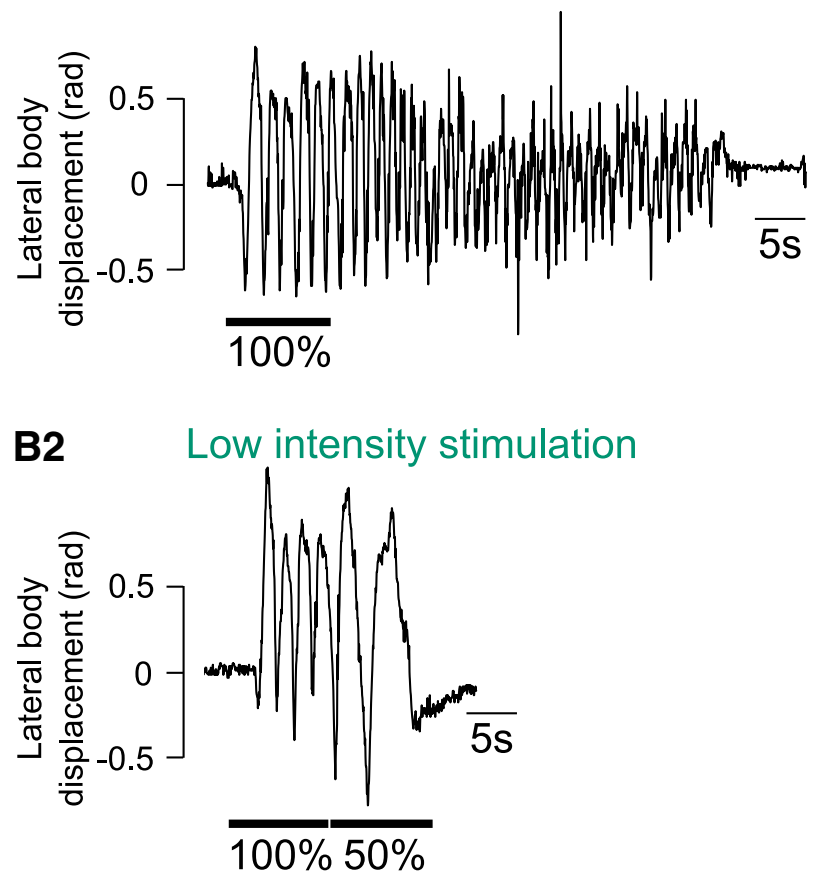

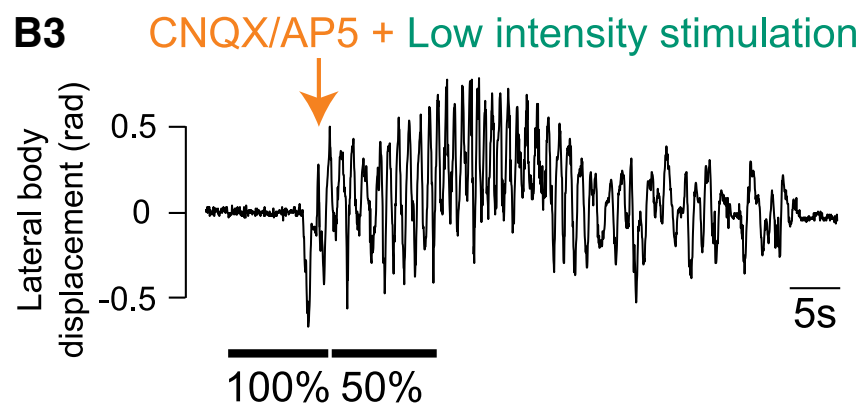

Figure 10. Effects of glutamatergic blockage in the stop cell region. $\boldsymbol{A}$, Schematic representation of the brainstem illustrating injection and stimulation sites. Note that the experiments were performed in a semi-intact preparation in which locomotion was induced and stopped by electrical stimulation of the MLR. A mixture of CNQX and AP5 was ejected bilaterally over the stop cell region in the caudal MRRN. B1, Swimming was induced with electrical MLR stimulation and stopped by applying a second MLR stimulation at a lower intensity at the end of the first MLR stimulation (B2). B3, Same as in B2 but after locally ejecting CNQX and AP5 over the stop cell region. $\boldsymbol{C}$, Bar graphs illustrating the average values obtained in five animals for the three conditions shown in $\boldsymbol{B}$. Data were normalized to the mean of control. Bars represent the mean \pm SEM of pooled data ( $n=25$ trials in 5 animals for each condition). ${ }^{* * *} p<0.001 ; n$.s. not statistically significant.

1984; Sirota et al., 2000; Brocard and Dubuc, 2003; for review see Ryczko and Dubuc, 2013). In the lamprey, three different RS cell populations were identified: start cells, maintain cells, and stop cells (Juvin et al., 2016). When the MLR is stimulated in resting animals, a descending start signal from the MLR activates all RS cell populations in the MRRN and initiates locomotion. The locomotor episode is maintained through the activity of a subgroup of RS cells, the maintain cells. We now show that MLR stimulation can also produce an opposite behavioral effect consisting in the termination of locomotion by providing a stop signal to RS cells that are crucial for stopping locomotion, the stop cells.

\section{Synaptic inputs to stop cells}

The study of RS cells that are localized in the brainstem and that could be involved in halting locomotion was performed only in a few vertebrate species (Xenopus tadpole: Perrins et al., 2002; cat: Takakusaki et al., 2003; mouse: Bouvier et al., 2015; Capelli et al., 2017; and lamprey: Juvin et al., 2016). Electrical, pharmacological, or optogenetic stimulation of these RS cell populations was shown to lead to the termination of ongoing locomotion. As yet, the detailed mechanisms responsible for activating these RS cells that stop locomotion have not been identified.

The MLR is known to project extensively to RS cells (Orlovskiü, 1970; Steeves and Jordan, 1984; Garcia-Rill and Skinner, 1987; Brocard and Dubuc, 2003; Brocard et al., 2010; Smetana et al., 2010; Bretzner and Brownstone, 2013; Ryczko et al., 2016). In the lamprey, these projections have been well characterized. Inputs from the MLR to RS cells were shown to differ in strength of connectivity depending on the localization of the RS cells in the hindbrain (Brocard and Dubuc, 2003). For example, rostral RS cells located in the MRRN receive stronger MLR inputs than those located more caudally in the PRRN. The connections from the MLR to RS cells were shown to be both monosynaptic and disynaptic (Brocard et al., 2010; Smetana et al., 2010) and glutamatergic and cholinergic projection neurons were identified to be involved in locomotor initiation and speed control (Brocard and Dubuc, 2003; Le Ray et al., 2003). Our anatomical data indicate that numerous MLR cells project to the area of the retic- 
ular formation that is rich in stop cells and electrophysiological data suggest that at least a part of the projections from the MLR to the stop cells is monosynaptic. Moreover, our results indicate that glutamatergic projections are involved in the MLRinduced termination of locomotion. For instance, injections of D-glutamate over the stop cell region significantly reduced the duration of an ongoing locomotor bout. Similar observations were previously made by Juvin et al. (2016). To further confirm the role of glutamate in the MLR-stop cell transmission, we have now shown that blocking glutamate receptors in the stop cell region prevented the reducing effect of a second low-intensity MLR stimulation on the duration of a locomotor bout. In addition, the activation of cholinergic receptors had no effect on the duration of the locomotor bout. This result is not surprising because it was shown previously that there is only a small component of MLR inputs to RS cells that is cholinergic (Le Ray et al., 2003).

Because locomotion could still end after blocking the glutamatergic excitation of stop cells, it is possible that there are also other neural mechanisms involved in the termination of locomotion. In mice, two different brainstem mechanisms have been described for halting locomotion. Glutamatergic V2a "stop cells" were shown to efficiently halt locomotion when activated optogenetically (Bouvier et al., 2015). Interestingly, these cells are located in the caudal pons/rostral medulla, a region that is very similar to that of the stop cells in the lamprey. In addition, that study showed that the mice V2a "stop cells" provide a descending excitatory projection to the spinal cord via glutamatergic inputs. It was also shown in mice that optogenetic activation of inhibitory RS cells halts locomotion (Capelli et al., 2017). The investigators proposed that inhibitory RS cells in different regions of the brainstem of mice could evoke different forms of behavioral arrest when activated. In the present study, it is not unlikely that a progressive decrease in descending excitation could be involved after the glutamatergic excitation to stop cells has been blocked. Therefore, it appears that there could be several means of halting locomotion.

\section{How the MLR controls the termination of locomotion}

Classically, the MLR has been described to initiate and control locomotion (for review, see Ryczko and Dubuc, 2013). The present findings indicating that activation of the MLR can also terminate locomotion were therefore unexpected. However, the MLR is a complex and large region in more recently evolved vertebrates, where it consists of several nuclei that seem to contribute in different ways to the locomotor repertoire. Sinnamon (1993) proposed that different MLR subregions control different behaviors such as appetitive, explorative, and defensive behavior. In addition, experiments in cats revealed that electrical stimulation of noncholinergic neurons of the cuneiform nucleus $(\mathrm{CnF})$ and pendunclopontine nucleus (PPN), which are considered to be parts of the MLR, triggers movement. Conversely, stimulation of cholinergic PPN neurons stops ongoing spontaneous walking and induces muscle atonia (Takakusaki et al., 2003, 2004; for review, see Takakusaki, 2008). With the development of optogenetic techniques, it has recently become possible to use a more controlled approach to examine the multiple behaviors induced by the MLR (Roseberry et al., 2016; Caggiano et al., 2018; Josset et al., 2018). Roseberry et al. (2016) demonstrated that glutamatergic MLR cells drive locomotion and cholinergic neurons modulate its speed. Conversely, local GABAergic neurons were shown to inhibit glutamatergic MLR cells and thus stop locomotion when activated (Roseberry et al., 2016). The contribution of glu- tamatergic neurons in the PPN and $\mathrm{CnF}$ to the locomotor output has also been examined in more detail (Caggiano et al., 2018; Josset et al., 2018). It was shown that glutamatergic neurons in both nuclei contribute to slow movements, but only glutamatergic $\mathrm{CnF}$ neurons can control high-speed locomotion. The PPN was therefore associated with slow exploratory movements and the $\mathrm{CnF}$ with fast escape behavior (Caggiano et al., 2018). These results were confirmed by another study in which glutamatergic $\mathrm{CnF}$ neurons were shown to initiate and accelerate locomotion and activation of glutamatergic PPN neurons produced slow walking movements. Additionally, cholinergic PPN neurons were shown to modulate locomotor speed (Josset et al., 2018). Together, the recent studies indicate that the mammalian MLR is divided into different regions that contribute to different locomotor functions. In contrast to this, the lamprey MLR is much smaller and, in the present work, we did not find a segregation of MLR cells projecting to the stop cell versus maintain cell regions. Therefore, the MLR of lampreys would be less clustered.

A salient finding in the present study is that stimulation of the same MLR site can produce opposite behaviors (initiation vs termination of locomotion) when changing the intensity of the MLR stimulation. It is possible that changing the stimulation intensity activates different subpopulations of neurons. For example, MLR cells projecting to the stop cells could have intrinsic properties (e.g., membrane resistance or threshold) that would differ from those of other MLR cells. The excitability of these MLR cells could also change depending on the behavioral state of the animal. For example, the excitability could increase during locomotion, allowing the MLR cells to be activated by lowintensity stimulation. Conversely, MLR cells projecting to start and maintain RS cells would be highly excitable at rest and their excitability would decrease during the active locomotor state. This could explain the observations made in the present study, in which the second stimulation produces a termination burst in stop cells, but no increased activity in maintain cells. The descending inputs from the MLR to stop cells would be more efficient when occurring during locomotion. Additional experiments are needed in the future to test this hypothesis.

\section{Conclusion}

Results from the present study provide a better understanding of the neural mechanisms responsible for stopping locomotion. We show that electrical stimulation of the same MLR site can elicit opposing effects (initiation and termination of locomotion) depending on the stimulation intensity. These results could be important for the clinical research field because deep-brain stimulation of the MLR is presently performed to reduce symptoms in Parkinson's disease patients (Stefani et al., 2007; Arnulf et al., 2010; Wilcox et al., 2011; for review, see Ryczko et al., 2013). Our results close a gap in knowledge relative to the neural mechanism responsible for terminating locomotion.

\section{References}

Antri M, Fénelon K, Dubuc R (2009) The contribution of synaptic inputs to sustained depolarizations in reticulospinal neurons. J Neurosci 29:11401151. CrossRef Medline

Arnulf I, Ferraye M, Fraix V, Benabid AL, Chabardès S, Goetz L, Pollak P, Debû B (2010) Sleep induced by stimulation in the human pedunculopontine nucleus area. Ann Neurol 67:546-549. CrossRef Medline

Bouvier J, Caggiano V, Leiras R, Caldeira V, Bellardita C, Balueva K, Fuchs A, Kiehn O (2015) Descending command neurons in the brainstem that halt locomotion. Cell 163:1191-1203. CrossRef Medline

Bretzner F, Brownstone RM (2013) Lhx3-Chx10 reticulospinal neurons in locomotor circuits. J Neurosci 33:14681-14692. CrossRef Medline 
Brocard F, Dubuc R (2003) Differential contribution of reticulospinal cells to the control of locomotion induced by the mesencephalic locomotor region. J Neurophysiol 90:1714-1727. CrossRef Medline

Brocard F, Ryczko D, Fénelon K, Hatem R, Gonzales D, Auclair F, Dubuc R (2010) The transformation of a unilateral locomotor command into a symmetrical bilateral activation in the brainstem. J Neurosci 30:523-533. CrossRef Medline

Cabelguen JM, Bourcier-Lucas C, Dubuc R (2003) Bimodal locomotion elicited by electrical stimulation of the midbrain in the salamander Notophthalmus viridescens. J Neurosci 23:2434-2439. CrossRef Medline

Caggiano V, Leiras R, Goñi-Erro H, Masini D, Bellardita C, Bouvier J, Caldeira V, Fisone G, Kiehn O (2018) Midbrain circuits that set locomotor speed and gait selection. Nature 553:455-460. CrossRef Medline

Capelli P, Pivetta C, Soledad Esposito M, Arber S (2017) Locomotor speed control circuits in the caudal brainstem. Nature 551:373-377. CrossRef Medline

Deliagina TG, Zelenin PV, Fagerstedt P, Grillner S, Orlovsky GN (2000) Activity of reticulospinal neurons during locomotion in the freely behaving lamprey. J Neurophysiol 83:853-863. CrossRef Medline

Di Prisco GV, Pearlstein E, Robitaille R, Dubuc R (1997) Role of sensoryevoked NMDA plateau potentials in the initiation of locomotion. Science 278:1122-1125. CrossRef Medline

Di Prisco GV, Pearlstein E, Le Ray D, Robitaille R, Dubuc R (2000) A cellular mechanism for the transformation of a sensory input into a motor command. J Neurosci 20:8169-8176. CrossRef Medline

Drew T, Dubuc R, Rossignol S (1986) Discharge patterns of reticulospinal and other reticular neurons in chronic, unrestrained cats walking on a treadmill. J Neurophysiol 55:375-401. CrossRef Medline

El Manira A, Pombal MA, Grillner S (1997) Diencephalic projection to reticulospinal neurons involved in the initiation of locomotion in adult lampreys Lampetra fluviatilis. J Comp Neurol 389:603-616. CrossRef Medline

Garcia-Rill E, Skinner RD (1987) The mesencephalic locomotor region. II. projections to reticulospinal neurons. Brain Res 411:13-20. CrossRef Medline

Garcia-Rill E, Skinner RD, Fitzgerald JA (1985) Chemical activation of the mesencephalic locomotor region. Brain Res 330:43-54. CrossRef Medline

Gariépy JF, Missaghi K, Chartré S, Robert M, Auclair F, Dubuc R (2012) Bilateral connectivity in the brainstem respiratory networks of lampreys. J Comp Neurol 520:1442-1456. CrossRef Medline

Grillner S, Wallén P, Saitoh K, Kozlov A, Robertson B (2008) Neural bases of goal-directed locomotion in vertebrates-an overview. Brain Res Rev 57:2-12. CrossRef Medline

Jackson AW, Pino FA, Wiebe ED, McClellan AD (2007) Movements and muscle activity initiated by brain locomotor areas in semi-intact preparations from larval lamprey. J Neurophysiol 97:3229-3241. CrossRef Medline

Jordan LM (1998) Initiation of locomotion in mammals. Ann N Y Acad Sci 860:83-93. CrossRef Medline

Josset N, Roussel M, Lemieux M, Lafrance-Zoubga D, Rastqar A, Bretzner F (2018) Distinct contributions of mesencephalic locomotor region nuclei to locomotor control in the freely behaving mouse. Curr Biol 28:884901.e3. CrossRef Medline

Juvin L, Grätsch S, Trillaud-Doppia E, Gariépy JF, Büschges A, Dubuc R (2016) A specific population of reticulospinal neurons controls the termination of locomotion. Cell Rep 15:2377-2386. CrossRef Medline

Kimura Y, Satou C, Fujioka S, Shoji W, Umeda K, Ishizuka T, Yawo H, Higashijima S (2013) Hindbrain V2a neurons in the excitation of spinal locomotor circuits during zebrafish swimming. Curr Biol 23:843-849. CrossRef Medline

Lee AM, Hoy JL, Bonci A, Wilbrecht L, Stryker MP, Niell CM (2014) Identification of a brainstem circuit regulating visual cortical state in parallel with locomotion. Neuron 83:455-466. CrossRef Medline

Le Ray D, Brocard F, Bourcier-Lucas C, Auclair F, Lafaille P, Dubuc R (2003) Nicotinic activation of reticulospinal cells involved in the control of swimming in lampreys. Eur J Neurosci 17:137-148. CrossRef Medline

Orlovskiĭ GN (1970) Relations between reticulo-spinal neurons and locomotor regions of the brain stem [Article in Russian]. Biofizika 15:171178. Medline

Paggett KC, Jackson AW, McClellan AD (2004) Organization of higher- order brain areas that initiate locomotor activity in larval lamprey. Neuroscience 125:25-33. CrossRef Medline

Perrins R, Walford A, Roberts A (2002) Sensory activation and role of inhibitory reticulospinal neurons that stop swimming in hatchling frog tadpoles. J Neurosci 22:4229-4240. CrossRef Medline

Ranck JB Jr (1975) Which elements are excited in electrical stimulation of mammalian central nervous system: a review. Brain Res 98:417-440. CrossRef Medline

Roseberry TK, Lee AM, Lalive AL, Wilbrecht L, Bonci A, Kreitzer AC (2016) Cell-type-specific control of brainstem locomotor circuits by basal ganglia. Cell 164:526-537. CrossRef Medline

Rovainen CM (1967) Physiological and anatomical studies on large neurons of central nervous system of the sea lamprey (Petromyzon marinus). I. Müller and Mauthner cells. J Neurophysiol 30:1000-1023. CrossRef Medline

Ryczko D, Dubuc R (2013) The multifunctional mesencephalic locomotor region. Curr Pharm Des 19:4448-4470. CrossRef Medline

Ryczko D, Grätsch S, Auclair F, Dubé C, Bergeron S, Alpert MH, Cone JJ, Roitman MF, Alford S, Dubuc R (2013) Forebrain dopamine neurons project down to a brainstem region controlling locomotion. Proc Natl Acad Sci U S A 110:E3235-E3242. CrossRef Medline

Ryczko D, Auclair F, Cabelguen JM, Dubuc R (2016) The mesencephalic locomotor region sends a bilateral glutamatergic drive to hindbrain reticulospinal neurons in a tetrapod. J Comp Neurol 524:1361-1383. CrossRef Medline

Ryczko D, Grätsch S, Schläger L, Keuyalian A, Boukhatem Z, Garcia C, Auclair F, Büschges A, Dubuc R (2017) Nigral glutamatergic neurons control the speed of locomotion. J Neurosci 37:9759-9770. CrossRef Medline

Shik ML, Severin FV, Orlovskiĭ GN (1966) Control of walking and running by means of electric stimulation of the midbrain [Article in Russian]. Biofizika 11:659-666. Medline

Sholomenko GN, Funk GD, Steeves JD (1991) Avian locomotion activated by brainstem infusion of neurotransmitter agonists and antagonists. I. Acetylcholine excitatory amino acids and substance P. Exp Brain Res 85:659-673. CrossRef Medline

Sinnamon HM (1993) Preoptic and hypothalamic neurons and the initiation of locomotion in the anesthetized rat. Prog Neurobiol 41:323-344. CrossRef Medline

Sirota MG, Di Prisco GV, Dubuc R (2000) Stimulation of the mesencephalic locomotor region elicits controlled swimming in semi-intact lampreys. Eur J Neurosci 12:4081-4092. CrossRef Medline

Skinner RD, Garcia-Rill E (1984) The mesencephalic locomotor region (MLR) in the rat. Brain Res 323:385-389. CrossRef Medline

Smetana R, Juvin L, Dubuc R, Alford S (2010) A parallel cholinergic brainstem pathway for enhancing locomotor drive. Nat Neurosci 13:731-738. CrossRef Medline

Steeves JD, Jordan LM (1984) Autoradiographic demonstration of the projections from the mesencephalic locomotor region. Brain Res 307:263276. CrossRef Medline

Stefani A, Lozano AM, Peppe A, Stanzione P, Galati S, Tropepi D, Pierantozzi M, Brusa L, Scarnati E, Mazzone P (2007) Bilateral deep brain stimulation of the pedunculopontine and subthalamic nuclei in severe Parkinson's disease. Brain 130:1596-1607. CrossRef Medline

Takakusaki K (2008) Forebrain control of locomotor behaviors. Brain Res Rev 57:192-198. CrossRef Medline

Takakusaki K, Kohyama J, Matsuyama K (2003) Medullary reticulospinal tract mediating a generalized motor inhibition in cats: III. Functional organization of spinal interneurons in the lower lumbar segments. Neuroscience 121:731-746. CrossRef Medline

Takakusaki K, Habaguchi T, Saitoh K, Kohyama J (2004) Changes in the excitability of hindlimb motoneurons during muscular atonia induced by stimulating the pedunculopontine tegmental nucleus in cats. Neuroscience 124:467-480. CrossRef Medline

Thiele TR, Donovan JC, Baier H (2014) Descending control of swim posture by a midbrain nucleus in zebrafish. Neuron 83:679-691. CrossRef Medline

Wilcox RA, Cole MH, Wong D, Coyne T, Silburn P, Kerr G (2011) Pedunculopontine nucleus deep brain stimulation produces sustained improvement in primary progressive freezing of gait. J Neurol Neurosurg Psychiatry 82:1256-1259. CrossRef Medline 